\title{
EL ACCESO A LA INFORMACIÓN EN MATERIA DE MEDIO AMBIENTE EN ESPAÑA: BALANCE Y RETOS DE FUTURO
}

\section{ACCESS TO ENVIRONMENTAL INFORMATION IN SPAIN: BALANCE AND FUTURE CHALLENGES}

\author{
JOSÉ ANTONIO RAZQUIN LIZARRAGA \\ Profesor asociado doctor \\ Universidad de Navarra \\ jrazquin!@gmail.com
}

Recibido: 27 de abril de 2018 / Aceptado: 5 de junio de 2018

RESUMEN: Este trabajo estudia la regulación específica del acceso a la información ambiental en España, tanto en su faceta activa (recogida y difusión) como pasiva (derecho de acceso mediante solicitud), establecida, en aplicación del Convenio de Aarhus, por la Ley 27/2006, que supuso un cambio de rumbo hacia la transparencia ambiental. Se analiza este régimen especial y su aplicación para mostrar los avances y las dificultades en la efectividad del acceso a la información ambiental, así como su relación con la posterior regulación general de la información pública en la Ley 19/2013. A la vista de este balance, se ofrecen propuestas de mejora en aras de una amplia y efectiva transparencia en materia de medio ambiente.

RESUM: Aquest treball estudia la regulació específica de l'accés a la informació ambiental a Espanya, tant en la faceta activa (recollida i difusió) com passiva (dret d'accés mitjançant sol-licitud), establerta, d'acord amb el Conveni d'Aarhus, per la Llei 27/2006, que va suposar un canvi de rumb cap a la transparència ambiental. Se n'analitza aquest règim especial i l'aplicació per mostrar els avanços i les dificultats en l'efectivitat de l'accés a la informació 
ambiental, així com la relació amb la posterior regulació general de la informació pública en la Llei 19/2013. A la vista d'aquest balanç, s'ofereixen propostes de millora en honor d'una transparència àmplia i efectiva en matèria de medi ambient.

ABSTRACT: This paper studies the specific regulation of access to environmental information in Spain, both in its active facet (collection and dissemination) and passive (access right by request), established, in application of the Aarhus Convention, by Law 27/2006 , which meant a change of direction towards environmental transparency. This special regime is analyzed and its application to show the advances and difficulties in the effectiveness of access to environmental information, as well as its relationship with the subsequent general regulation of public information in Law 19/2013. In view of this balance, proposals for improvement are offered in the interest of a broad and effective environmental transparency.

PALABRAS CLAVE: información ambiental - derecho de acceso a la información ambiental - difusión de la información ambiental - medio ambiente — transparencia.

PARAULES CLAU: Informació ambiental - Dret d'accés a la informació ambiental - Difusió de la informació ambiental - Medi ambient Transparència.

KEY WORDS: Environmental information - Right of access to environmental information - Dissemination of environmental information - Environment Transparency.

SUMARIO: I. Veinte años del Convenio de Aarhus: el camino hacia la transparencia. II. Nuevo paradigma sectorial: derecho a saber en materia ambiental. 1. Finalidad: principio general de transparencia ambiental o máxima apertura informativa. 2. Sujetos: público y autoridades públicas. 3. Objeto: definición de información ambiental. III. Difusión de la información ambiental por las autoridades públicas. IV. El derecho de acceso a la información ambiental mediante solicitud. 1. Configuración como un derecho legal específico. 2. Procedimiento. 3. Forma o formato de la información. 4. Contraprestación económica. 5. Límites al acceso a la información ambiental. V. Protección administrativa y judicial del acceso a la información ambiental. VI. El nuevo paradigma general de la información pública: Ley de Transparencia y Acceso a la Información Ambiental. 1. Breve contraste entre régimen general y regulación 
especial. 2. La relación entre la ley general y la ley sectorial en cuanto al acceso a la información ambiental. VII. Retos de futuro. VIII. Bibliografía.

\section{VEINTE AÑOS DEL CONVENIO DE AARHUS: EL CAMINO HACIA LA TRANSPARENCIA}

La transparencia es un factor esencial de la democracia. El acceso a la información pública es un pilar del buen gobierno y de la gobernanza al promover la transparencia, fomentar la participación pública y propiciar el control democrático de las autoridades públicas actuando como acicate contra la corrupción. Su relevancia general se acrecienta en materia de medio ambiente en cuanto instrumento crucial para materializar la protección del medio ambiente y el desarrollo sostenible.

Sin embargo, el camino para implementar los valores de transparencia y participación pública no ha sido fácil. En España el punto de partida preconstitucional era el secreto o la opacidad informativa. Los primeros pasos posconstitucionales muestran un desarrollo tímido y restrictivo ${ }^{1}$, faltando una ley general del acceso a la información pública² .

Un primer avance se produjo precisamente en el campo ambiental. La Ley 38/1995, de 12 de diciembre, sobre el derecho de acceso a la información en materia de medio ambiente, en transposición de la Directiva 90/313/CEE, reguló el derecho de acceso a la información en materia de medio ambiente, estableciendo un régimen específico más amplio que la regulación general (Ley 30/1992), si bien insuficiente y laxo para un ejercicio efectivo de ese derecho, como pusieron de manifiesto su modificación por la Ley 55/1999, de 29 de

\footnotetext{
${ }^{1}$ La Ley 30/1992, de 26 de noviembre, de régimen jurídico de las Administraciones públicas y del procedimiento administrativo común, incorporó la transparencia como principio general de la actuación administrativa en sus relaciones con los ciudadanos (art. 3.5, en la redacción dada por la Ley 4/1999), reconoció a los ciudadanos, en sus relaciones con las Administraciones públicas, el derecho al acceso a los registros y archivos de las Administraciones públicas en los términos previstos en la Constitución y en esta u otras leyes [arts. 35.h)], y fijó una regulación general de este derecho de carácter limitado y restrictivo (art. 37). En su desarrollo, primero la Ley $7 / 1985$, de 2 de abril, reguladora de las Bases del Régimen Local (objeto de ulteriores modificaciones), reconoció a los vecinos el derecho a ser informados y dirigir solicitudes a la Administración municipal en relación con todos los expedientes y documentación municipal [art. 18.g)] y contempló la información y participación ciudadanas (arts. 69 a 72).

2 No obstante, la Ley 30/1992 recoge el principio de transparencia como rector de las relaciones de las Administraciones públicas con los ciudadanos (art. 3.5, en la redacción dada por la Ley 4/1999).
} 
diciembre, de medidas fiscales, administrativas y del orden social, para cumplir cabalmente las exigencias europeas, y los pronunciamientos judiciales favorecedores de una interpretación adecuada y aperturista de dicha normativa ${ }^{3}$.

El cambio de rumbo hacia la transparencia se impulsó en el campo ambiental a partir del Convenio sobre el acceso a la información, la participación del público en la toma de decisiones y el acceso a la justicia en asuntos ambientales, hecho en el seno de la Comisión Económica para Europa de Naciones Unidas (CEPE) en Aarhus (Dinamarca) el 25 de junio de 1998, que, en aplicación del principio 10 de la Declaración de Río sobre Medio Ambiente y Desarrollo de 1992, establece los tres pilares interdependientes de la democracia ambiental. El Convenio de Aarhus, de novedosa y destacada significación ${ }^{4}$, regula específicamente el derecho a saber en el campo ambiental en sus dimensiones pasiva - acceso mediante solicitud- (art. 4) y activa — recogida y difusión$(\text { art. } 5)^{5}$. Es un instrumento vivo en evolución ${ }^{6}$ y constante avance aplicativo, con un mecanismo de control de su cumplimiento. Era la normativa más avanzada hacia el nuevo paradigma de la transparencia, siendo, una vez

\footnotetext{
${ }^{3}$ Así, la STS de 17 de febrero de 2004 (recurso de casación núm. 3457/2000), que declara que las actas de inspección no son documento inconcluso. Véase CASADO CASADO, L., "EI derecho de acceso a la información ambiental a través de la jurisprudencia", Revista de Administración Pública, núm. 178, 2009, pp. 281-322.

${ }^{4}$ Es un nuevo tipo de acuerdo ambiental por su finalidad (contribuir a la realización del derecho de todos, generaciones presentes y futuras, a un medio ambiente saludable), por su objeto (los tres pilares de información, participación y justicia) y por la pretensión de efectividad (derechos prácticos de las personas). El Convenio cuenta con una guía de aplicación: The Aarhus Convention: An Implementation Guide (segunda edición, junio 2014).

5 Entre otros, RAZQUIN LIZARRAGA, J. A., "El Convenio de Aarhus", Actualidad Jurídica Aranzadi, núm. 670, 2005; y PIGRAU SOLÉ, A. (dir.), Acceso a la información, participación pública y acceso a la justicia en materia de medio ambiente: diez años del Convenio de Aarhus, Atelier, Barcelona, 2008.

${ }^{6}$ Para cerrar la brecha inicial, el Convenio fue modificado en 2005 mediante una enmienda que introducía un nuevo artículo 6 bis y anexo 1 bis sobre participación pública en las decisiones sobre liberación voluntaria en el ambiente y puesta en el mercado de GMO (aprobada por la Unión Europea con efectos de 1 de febrero de 2008 y ratificada por España con efectos de 21 de febrero de 2008); y ha sido desarrollado por el Protocolo de la CEPE/ONU sobre registros de emisiones y transferencias de sustancias contaminantes, hecho en Kiev en 2003. Este protocolo, aprobado por la Unión Europea y ratificado por España (Instrumento de Ratificación de 28 de agosto de 2009; BOE, núm. 285, de 26 de noviembre de 2009), fue aplicado por el Reglamento (CE) núm. 166/2006 del Parlamento Europeo y del Consejo, de 18 de enero de 2006, relativo al establecimiento de un registro europeo de emisiones y transferencias de contaminantes, y por el Real Decreto 508/2007, de 20 de abril, por el que se regula el suministro de información sobre emisiones del Reglamento E-PRTR y de las autorizaciones ambientales integradas.
} 
ratificado $^{7}$, un texto jurídicamente vinculante, aunque necesitado de su aplicación en el ámbito europeo e interno en cumplimiento de los compromisos que entraña, en particular, el establecimiento de un marco preciso, transparente y coherente (art. 3$)^{8}$.

La Unión Europea ha aplicado respecto de los Estados miembros los pilares de información y de participación del Convenio de Aarhus ${ }^{9}$. El primero mediante la Directiva 2003/4/CE del Parlamento Europeo y del Consejo, de 28 de enero de 2003, relativa al acceso del público a la información medioambiental y por la que se deroga la Directiva 90/313/CEE del Consejo, que incorpora algunos avances ${ }^{10}$. Por otro lado, respecto de las instituciones comunitarias, el Reglamento (CE) núm. 1367/2006 del Parlamento Europeo y del Consejo, de 6 de septiembre de 2006, establece la aplicación, en el ámbito de las instituciones y los organismos comunitarios, de las disposiciones del Convenio de Aarhus sobre el acceso a la información, la participación del público en la toma de decisiones y el acceso a la justicia en materia de medio ambiente.

En España, la aplicación del Convenio de Aarhus y la transposición de las directivas comunitarias se llevaron a cabo por la Ley 27/2006, de 18 de julio, por la que se regulan los derechos de acceso a la información, de participación pública y de acceso a la justicia en materia de medio ambiente (LIPPJMA). Se

7 La Unión Europea aprobó el Convenio de Aarhus en 2005 (Decisión 2005/370/CE del Consejo, de 17 de febrero de 2005, DOUE L 124, de 17 de mayo de 2005, y por Decisión 2006/957/CE del Consejo, de 18 de diciembre de 2006, aprobó la enmienda al Convenio), y en España, tras su ratificación (Instrumento de Ratificación, de 15 de diciembre de 2004, BOE, núm. 40, de 16 de febrero de 2005, con efectos de 29 de marzo de 2005), forma parte de nuestro ordenamiento jurídico y vincula a los poderes públicos y a los ciudadanos (art. 96.1 CE).

${ }^{8}$ Las SSTS de 25 de junio de 2008 (recurso de casación núm. 905/2007) y de 7 de julio de 2017 (recurso de casación núm. 1783/2015) reflejan que la evolución normativa cada vez destaca más la relevancia del Convenio de Aarhus.

${ }^{9}$ El primer pilar por la Directiva 2003/4/CE y el segundo por la Directiva 2003/35/CE. En cambio, no ha aplicado el tercer pilar al no haberse adoptado la propuesta de Directiva sobre acceso a la justicia en materia de medio ambiente (COM/2003/0624 final, 24.10.2003).

10 Esta directiva amplía el concepto de información ambiental al incluir en este las informaciones relativas a las actividades y medidas destinadas a proteger los factores y elementos del medio ambiente y los informes sobre la ejecución de la legislación medioambiental, no contemplados anteriormente; extiende el acceso a la información poseída en nombre de las autoridades públicas; refuerza la calidad de la información medioambiental a difundir, precisando, asegurando (información en caso de documentación en curso de elaboración) e incluso restringiendo (exclusión de emisiones en el medio ambiente) la aplicación de limitaciones; fija supuestos de gratuidad en el suministro de información; y prevé el acceso a la justicia también por los perjudicados por la revelación de la información. Véase GONZÁLEZ BONDIA, A., "La regulación comunitaria europea del acceso a la información, la participación pública y el acceso a la justicia en materia de medio ambiente en sus Estados miembros", Pigrau Solé (dir.), Acceso a la información ... cit., pp. 85-118. 
instaura un nuevo paradigma de transparencia y participación en materia de medio ambiente mediante una regulación avanzada que mejora notablemente el régimen precedente y es más amplia que el régimen general, donde todavía no se contaba con una ley general de transparencia o información pública ${ }^{11}$.

Sin embargo, se ha producido una importante evolución normativa posterior, tanto a nivel estatal como autonómico, con la adopción de normas sobre transparencia y acceso a la información pública ${ }^{12}$. La Ley 19/2013, de 9 de diciembre, de transparencia, acceso a la información pública y buen gobierno (LTAIBG), que tiene en cuenta la regulación específica de la LIPPJMA, adopta el paradigma de la transparencia y constituye la regulación común o general del acceso a la información pública, archivos y registros a la que remite la legislación de procedimiento administrativo común ${ }^{13}$.

El vigésimo aniversario del Convenio de Aarhus justifica analizar el régimen y la aplicación del primer pilar de la democracia ambiental a fin de ofrecer un balance y propuestas de futuro ${ }^{14}$. A partir de su regulación en la LIPPJMA y a la luz de la experiencia y la jurisprudencia, se examinan los aspectos siguientes: los elementos generales del derecho a saber en el medio ambiente; la faceta activa o difusión de la información ambiental; la dimensión pasiva o derecho de acceso a la información ambiental; la incidencia de la posterior legislación general sobre transparencia en el campo ambiental; $\mathrm{y}$, finalmente, las propuestas de mejora o retos de futuro para lograr la plena normalización y efectividad del acceso a la información ambiental.

\section{NUEVO PARADIGMA SECTORIAL: DERECHO A SABER EN MATERIA}

\section{AMBIENTAL}

11 Por todos, RAZQUIN LIZARRAGA, J. A. y RUIZ DE APODACA ESPINOSA, Á. M., Información, Participación y Justicia en materia de medio ambiente. Comentario sistemático a la Ley 27/2006, de 18 de julio, Aranzadi, Cizur Menor, 2007.

${ }^{12}$ A nivel estatal, la Ley $37 / 2007$, de 16 de noviembre, sobre reutilización de la información del sector público, y la Ley 11/2007, de 22 de junio, de acceso electrónico de los ciudadanos a los Servicios Públicos. La mayoría de las comunidades autónomas han aprobado sus propias leyes de transparencia o buen gobierno.

${ }_{13}$ Primero los artículos 35.h) y 37 de la Ley 30/1992 (en la redacción dada por la propia Ley 19/2013) y ahora el artículo 13.d) de la Ley 39/2015, de 1 de octubre, del Procedimiento Administrativo Común de las Administraciones Públicas (LPACAP).

${ }^{14}$ Véase CASADO CASADO, L., "El acceso a la información ambiental en España: luces y sombras", Derecho PUCP: Revista de la Facultad de Derecho, núm. 70, 2013, pp. 241-278. 
La Ley 27/2006, en sintonía con el Convenio de Aarhus, alumbra un nuevo marco jurídico de la democracia ambiental en desarrollo de la faceta procedimental del principio constitucional de protección del medio ambiente (art. $45 \mathrm{CE}$ ) y de los principios constitucionales de participación efectiva (art. $9.2 \mathrm{CE}$ ) y de transparencia (art. $105 \mathrm{CE}$ ); regula conjuntamente los tres derechos, lo que refleja su interdependencia y carácter instrumental y finalista en aras de la protección del medio ambiente y la materialización del desarrollo sostenible; y pretende, tratando de superar la tradición formalista, asegurar unos derechos reales y efectivos que puedan ejercitarse de forma práctica.

La LIPPJMA, tras las disposiciones comunes (título I, arts. 1-4), establece un régimen especial y avanzado del acceso a la información ambiental (título II, arts. 5-15) más amplio que el sectorial precedente ${ }^{15}$. Es una legislación primordialmente básica y transversal aplicable directamente a todos los sectores ambientales, sin perjuicio de algunas especialidades en particular en cuanto a la difusión ${ }^{16}$, que desplaza y se superpone en materia ambiental a otras regulaciones generales más restrictivas (leyes de procedimiento administrativo común y de régimen local).

\section{Finalidad: principio general de transparencia ambiental o máxima apertura informativa}

Esta regulación específica pivota sobre el nuevo paradigma sectorial del derecho a saber en la medida en que pretende atribuir al público el derecho de acceso más amplio posible a la información ambiental, en razón de su esencial papel en la concienciación o sensibilización de la sociedad en los asuntos ambientales, como factor indispensable para el cabal ejercicio de la participación ciudadana ${ }^{17}$ y eficaz instrumento de control de la legalidad y de la responsabilidad de las autoridades públicas. Se trata —como señala el preámbulo de la LIPPJMA - de superar las dificultades y los obstáculos

15 La STSJ Canarias (Las Palmas) 402/2017, de 18 de noviembre (recurso contenciosoadministrativo núm. 277/2012), se refiere a la amplitud de los derechos de información en la legislación ambiental.

${ }^{16}$ La legislación sectorial ambiental se remite a la LIPPJMA y, a diferencia del acceso a la información pública, ha sido objeto de escaso desarrollo autonómico.

17 Así lo indica la STSJ Comunidad Valenciana 1960/2008, de 22 de diciembre (recurso contencioso-administrativo núm. 349/2007). 
apreciados bajo la regulación precedente y en la práctica, con el objetivo de que toda persona, sin discriminación ni exigencia o traba alguna, pueda obtener la información ambiental que desee ${ }^{18}$.

Por ello, la regla general es el acceso a la información ambiental, configurándose las limitaciones como excepciones a esa regla general. La materialización del principio general de transparencia que preside este primer pilar $^{19}$ requiere tres factores: una adecuada regulación, la disposición de los medios (organizativos, personales y materiales) necesarios, y su aplicación efectiva mediante un talante transparente y abierto de las autoridades públicas.

El primer pilar presenta dos facetas: la vertiente activa o la obligación de las autoridades públicas de difundir la información ambientalmente relevante por parte de las autoridades públicas, que deben recogerla y hacerla pública sin necesidad de que medie una petición previa (arts. 1.2 y 6-9 LIPPJMA); y la vertiente pasiva o el derecho a obtener información que esté en poder de las autoridades públicas mediante solicitud (arts. 1.1, 3.1 y 10-12 LIPPJMA). Ambas vertientes están interconectadas: la difusión de la información ambiental permite su directo conocimiento y, en caso de que no se haya difundido, la solicitud de información se satisface con la comunicación del lugar donde se puede acceder a dicha información o la remisión en el formato disponible [último inciso del artículo 11.1.a) LIPPJMA].

Para materializar este principio general de máximo acceso a la información ambiental, se fijan obligaciones generales de las autoridades públicas en materia de información ambiental (capítulo I del título II, art. 5 LIPPJMA): los deberes se imponen solo a las Administraciones públicas (art. 5.1) y las medidas se refieren a las autoridades públicas (art. 5.2 y 5.3 LIPPJMA).

Los deberes generales impuestos a las Administraciones públicas son los seis siguientes: la información de forma adecuada al público sobre los tres derechos y las vías para su ejercicio; la información, el consejo y el asesoramiento para su recto ejercicio; la elaboración y publicación de listas de autoridades públicas en atención a la información ambiental que obre en su poder; la asistencia por

18 La STS de 13 de marzo de 2014 (recurso de casación núm. 3933/2011) destaca las diferencias y los avances respecto de la Ley 38/1995.

${ }^{19}$ STS de 29 de noviembre de 2011 (recurso de casación núm. 2071/2008) y STSJ Andalucía (Granada) 2325/2012, de 23 de julio (recurso contencioso-administrativo núm. 681/2007). 
su personal al público cuando trate de acceder a la información ambiental ${ }^{20}$; el fomento del uso de las tecnologías de la información y de las telecomunicaciones para facilitar el acceso a la información; y el aseguramiento del principio de agilidad en la tramitación y resolución de las solicitudes de información ambiental (art. 5.1 LIPPJMA). Además, se impone a las autoridades públicas la obligación de velar, en la medida de sus posibilidades, para que la información recogida por ellas o la recogida en su nombre esté actualizada y sea precisa y susceptible de comparación (art. 5.2 LIPPJMA). Para materializar esas obligaciones, las autoridades públicas deben adoptar las medidas necesarias para hacer efectivo el ejercicio del derecho de acceso y, al menos, una de las tres siguientes: la designación de unidades responsables de información ambiental; la creación y el mantenimiento de medios de consulta de la información solicitada; o la creación de registros o listas de la información ambiental que obre en poder de las autoridades públicas o puntos de información, con indicaciones claras sobre dónde puede encontrarse dicha información (art. 5.3 LIPPJMA). En suma, se trata de facilitar la practicabilidad real del acceso, articulando mecanismos y personal para la asistencia al público y facilitando la accesibilidad a la información.

Tales obligaciones se vienen implantando a través de las páginas web de los departamentos ambientales de las Administraciones públicas, que incluyen un apartado relativo a los derechos ambientales, recogiendo sus aspectos básicos y la normativa de aplicación; facilitan información sobre cuestiones que pueden suscitarse para ejercitar el derecho; y prevén, en algunos casos, buzones genéricos de obtención de información y también específicos para la presentación de solicitudes de acceso a la información. Asimismo, la Administración del Estado y las comunidades autónomas han publicado sus respectivas listas unificadas de autoridades públicas, cuya importancia no es desdeñable por cuanto permiten su identificación y evitan confusiones al público, si bien su formato y contenido no son homogéneos ${ }^{21}$ y no incluyen a

\footnotetext{
${ }^{20}$ A tal fin, se prevé un plan de formación específico en el marco de la Administración del Estado tendente a sensibilizar al personal a su servicio respecto de los derechos y las obligaciones reconocidos en la Ley (disposición adicional undécima LIPPJMA).

${ }^{21}$ Así, en algunos casos la referencia a la Administración autonómica se limita al departamento competente en materia de medio ambiente (Cataluña: http://territori.gencat.cat/es/01_departament/03_atencio_a_la_ciutadania/04_dret_dacces_a_la
} 
sujetos privados del segundo bloque de autoridades públicas ${ }^{22}$. Además, muchas Administraciones públicas han creado una unidad responsable de información ambiental, que aparece identificada en la web y con la cual se facilita el contacto.

En último término, el fomento de las nuevas tecnologías de la información se ha visto superado por la legislación posterior, que se decanta por la Administración electrónica y regula el derecho y la obligación de relacionarse electrónicamente con las Administraciones públicas (art. 14 LPACAP). En la práctica, la publicidad activa se realiza por medios electrónicos y se facilita la presentación de solicitudes por correo electrónico ${ }^{23}$, si bien persisten algunas dificultades en el suministro de la información en formato electrónico ${ }^{24}$.

\section{Sujetos: público y autoridades públicas}

Los sujetos intervinientes en el acceso a la información son las autoridades públicas, como obligadas a suministrar la información, y el público, a quien se facilita la información ambiental.

El público es toda persona, física o jurídica, así como sus asociaciones, organizaciones y grupos (art. 2.1 LIPPJMA). Un concepto amplio y abierto que se perfila respecto del derecho a la información ambiental (art. 3 LIPPJMA).

La definición de autoridades públicas es un aspecto relevante del primer pilar por determinar los sujetos obligados a facilitar la información ambiental. La

\footnotetext{
_informacio_ambiental/03_autoritats_publiques/), mientras que en otros se incluyen también otros departamentos autonómicos (Comunidad de Madrid: http://www.madrid.org/cs/Satellite?c=CM_InfPractica_FA\&cid=1142581282904\&idConsejeria=1 109266187260\&idListConsj $=1109265444710 \&$ idOrganismo $=1109266227503 \&$ language $=e s \& p a$ gename $=$ ComunidadMadrid\%2FEstructura \&pv=1354412362687\&sm=1109266100977).

${ }_{22}$ En la Comunidad de Madrid la lista de autoridades públicas da acceso a los listados de autoridades públicas en materia de información ambiental en las diferentes unidades y organismos competentes (ayuntamientos de la Comunidad de Madrid; Consejería de Medio Ambiente, Administración Local y Ordenación del Territorio; otras consejerías de la Comunidad de Madrid; comunidades autónomas; y ministerio con competencias en medio ambiente), pero no aparecen sujetos privados comprendidos en el segundo bloque de la definición de autoridades públicas.

${ }^{23}$ En este sentido, la Administración General del Estado estaba obligada a establecer registros telemáticos para la resolución de los procedimientos relativos a solicitudes de información ambiental (disposición adicional novena LIPPJMA).

${ }^{24}$ Así lo pone de relieve la Sugerencia del Defensor del Pueblo de 21 de diciembre de 2017 (queja 17007433), que recomienda la adopción de medidas para garantizar el acceso electrónico al contenido de la documentación que se someta a información pública con base en el artículo 5.4 de la Ley 19/2013.
} 
LIPPJMA fija una noción, más amplia que la de la normativa precedente, que incluye en este primer pilar dos bloques ${ }^{25}$ : 1) las autoridades públicas en sentido estricto, para las que basta tal condición, que comprende los Gobiernos, las Administraciones públicas, los órganos públicos consultivos y las corporaciones de derecho público y demás personas físicas y jurídicas cuando ejerzan, con arreglo a la legislación vigente, funciones públicas, incluidos los notarios y registradores (art. 2.4.1 LIPPJMA); y 2) otras autoridades públicas en sentido amplio por su conexión con el medio ambiente, a fin de cubrir el fenómeno de la privatización y los nuevos métodos de prestación de servicios públicos tradicionales con relevancia ambiental, que comprende a las personas cuando tienen responsabilidades públicas, ejercen funciones públicas o prestan servicios públicos relacionados con el medio ambiente bajo la autoridad de cualquiera de las anteriores autoridades públicas (art. 2.4.2 LIPPJMA) ${ }^{26}$. Ello incluye a personas privadas como son las sociedades mercantiles públicas, los contratistas o concesionarios, los servicios de interés general regulados o las empresas de certificación o auditoría cuando sus actividades tengan relación con el medio ambiente ${ }^{27}$. Quedan fuera las autoridades legislativas y judiciales, pero solo cuando desempeñen tales funciones (artículo 2.4.3 LIPPJMA) ${ }^{28}$.

${ }^{25}$ A diferencia del Convenio (art. 2.2) y de la Directiva (art. 2.2), que tienen tres letras o bloques; el segundo de ellos está referido a "las personas físicas o jurídicas que ejercen, en virtud del Derecho interno, funciones administrativas públicas, en particular tareas, actividades o servicios específicos relacionados con el medio ambiente".

${ }^{26}$ De acuerdo con la STJUE de 19 de diciembre de 2013 (C-279/12, Fish Legal y Shirley), para determinar si una entidad (empresas de saneamiento y suministro de agua) puede ser calificada como personas jurídicas que ejercen en virtud del derecho interno funciones administrativas públicas, debe apreciarse si esas entidades, en virtud del derecho nacional que les es aplicable, disponen de potestades exorbitantes respecto a las reglas aplicables en las relaciones entre personas de derecho privado; las empresas que prestan servicios públicos relacionados con el medio ambiente bajo el control de una autoridad pública en sentido estricto deberían ser calificadas como autoridades públicas si esas empresas no determinan con autonomía real la manera de prestar esos servicios, dado que aquella autoridad pública puede influir de forma decisiva en la acción de esas empresas en el ámbito del medio ambiente; y una persona que entra en el ámbito de esa disposición constituye una autoridad pública en lo que atañe a todas las informaciones medioambientales que obran en su poder, si bien no está obligada a comunicar información medioambiental que no guarde relación con la prestación de esos servicios.

27 Para las personas del segundo bloque bajo su autoridad, la Administración General del Estado podrá reservarse la resolución de las solicitudes de información ambiental (disposición adicional cuarta LIPPJMA).

${ }^{28}$ Como señala la STJUE de 18 de julio de 2013 (C-515/11, Deutsche Umwelthilfe eV), esta previsión no puede atañer a los ministerios cuando elaboran y adoptan disposiciones normativas de rango inferior a la ley. 


\section{Objeto: definición de información ambiental}

El aspecto determinante de esta regulación especial reside en el objeto, constituido por la información ambiental que obre en poder de las autoridades públicas o en el de otros sujetos que la posean en su nombre (art. 1.1 LIPPJMA). Por lo tanto, la definición de información ambiental es un factor clave que se concreta mediante un concepto amplio y enunciativo en torno a tres elementos, los dos primeros genéricos y el último específico o distintivo ${ }^{29}$.

El primer componente es la información, que no puede confundirse con el documento o soporte de ella, que es indiferente. La forma es universal, por lo que comprende toda información en forma escrita, visual, sonora, electrónica o en cualquier otra forma (inciso inicial, art. 2.3 LIPPJMA).

El segundo elemento consiste en la disponibilidad de la información ambiental por las autoridades públicas tanto de forma directa (información que obra en poder de las autoridades públicas, artículo 2.4) como indirecta (información poseída en nombre de las autoridades públicas, artículo 2.5 LIPPJMA).

$Y$ el tercer y distintivo ingrediente es el criterio de afectación, al referirse la información a una especie o área específica, el medio ambiente ${ }^{30}$, que se intenta precisar de forma descriptiva y abierta mediante seis categorías: 1) la situación de los elementos ambientales, con una amplia lista ejemplificativa y no exhaustiva, que incluye la diversidad biológica y sus elementos, incluidos los organismos modificados genéticamente; 2) los factores o agentes físicos o naturales que inciden o pueden incidir sobre los elementos del medio ambiente contemplados en la primera categoría; 3) las medidas, como políticas, normas, planes, programas, acuerdos o actividades, que afecten a las dos categorías precedentes $^{31}$; 4) los informes sobre ejecución de la legislación medioambiental; 5) análisis coste-beneficio y otros análisis y supuestos económicos utilizados en las tomas de decisiones; y 6) el estado de la salud y

29 Téngase en cuenta el apartado primero ("Definición de información ambiental") de la Orden AAA/1601/2012.

30 BERTAZO, S., "El acceso a la información ambiental en la Unión Europea. La normativa general y los aspectos relevantes para el derecho al agua", Revista General de Derecho Administrativo, núm. 46, 2107.

${ }^{31}$ Como señala la Orden AAA/1601/2012 (apartado primero), el término medidas incluye todas las formas de ejercicio de la actividad administrativa. 
la seguridad de las personas, a la que sigue una lista enunciativa que se conecta con las tres primeras categorías.

Esta fórmula amplia, descriptiva y abierta no tiene carácter omnicomprensivo o ilimitado ${ }^{32}$, suscitándose problemas aplicativos por la labilidad del criterio de afectación —no explicitado en la jurisprudencia comunitaria-, que en algunos casos se resuelven en sentido inclusivo ${ }^{33}$, pero en otros, en especial en cuanto a los aspectos orgánicos, económicos y contractuales, que quedan fuera pese a concurrir alguna conexión ambiental ${ }^{34}$. Por otro lado, su componente genérico motiva que, pese a su especificidad, puedan producirse solapes no solo con el régimen general —como luego se verá-, sino también con previsiones sectoriales sobre acceso a la información, como es la legislación urbanística con aplicación conjunta de $\operatorname{ambas}^{35}$, si bien la urbanística pudiera otorgar mayor cobertura ${ }^{36}$.

32 STJCE de 17 de junio de 1998 (C-321/96, Mecklenburg).

${ }^{33}$ Son información ambiental: planes de labores en el ámbito de la legislación de minas (STSJ País Vasco 605/2011, de 21 de septiembre, recurso contencioso-administrativo núm. 474/2009), información sobre la potabilidad del agua (STSJ Extremadura 153/2013, de 24 de septiembre, recurso de apelación núm. 126/2013), informe geomorfológico relacionado con deslinde de playa y barranco (Sugerencia del Defensor del Pueblo de 30 de marzo de 2016, queja núm. 15016059), proyecto de distribución de energía eléctrica en espacio de la Red Natura 2000 (Sugerencia del Defensor del Pueblo de 30 de marzo de 2017, queja núm. 16014171), informe con información sobre ejemplares de especies piscícolas y sus efectos sobre otras especies protegidas (Sugerencia del Defensor del Pueblo de 16 de diciembre de 2016, queja núm. 13026497), efectos de un incendio forestal y medidas de prevención y correctoras adoptadas (Sugerencia del Defensor del Pueblo de 18 de agosto de 2017, queja núm. 17007078) y expedientes de autorización de medicamentos de uso veterinario que contienen diclofenaco (Sugerencia del Defensor del Pueblo de 8 de noviembre de 2017, queja núm. 17011456-01). También la información aportada en el marco de un procedimiento nacional de autorización o de ampliación de la autorización de un producto fitosanitario con el fin de determinar el contenido máximo de un plaguicida, componente de este o productos de transformación que puede haber en los alimentos o bebidas (STJUE de 16 de diciembre de 2010 [C-266/09, Stichting Natuur en Milieu y otros]).

34 Convocatoria del procedimiento abierto para la ejecución de las obras del Centro Penitenciario (SAN de 16 de diciembre de 2009, recurso de apelación núm. 194/2009), procedimiento de otorgamiento de aval a la concesionaria del aeropuerto de la Región de Murcia (STSJ Murcia 826/2013, de 4 de noviembre, recurso contencioso-administrativo núm. 1166/2010), adjudicación del contrato administrativo de concesión de la gestión indirecta del servicio municipal de aguas (STSJ Castilla y León, Burgos, 28/2015, de 6 de febrero, recurso de apelación núm. 172/2014); o estudio técnico que pretende definir las características técnicas del equipamiento que ha de contratarse para un proyecto al no tratar de la inmediata preservación de los elementos del medio ambiente, zonas marinas y costeras o la diversidad biológica, sino de un estudio destinado a la contratación administrativa (SAN 452/2016, de 30 de junio, recurso contencioso-administrativo núm. 3152/2014). Véase GARCÍA URETA, A. M., "Ejecución de la política ambiental europea, transparencia y acceso a la información sobre aspectos económicos", García Macho, R. J., Ordenación y transparencia económica en el Derecho público y privado, Marcial Pons, Madrid, 2014, pp. 213-242.

${ }^{35}$ STSJ Castilla-La Mancha 239/2017, de 20 de octubre (recurso de apelación núm. 148/2016), sobre petición de información urbanística. La información sobre licencias municipales de 


\section{DIFUSIÓN DE LA INFORMACIÓN AMBIENTAL POR LAS AUTORIDADES PÚBLICAS}

La LIPPJMA tiene por objeto —al igual que la Directiva-garantizar la difusión y puesta a disposición del público de la información ambiental, de manera paulatina y con el grado de amplitud, de sistemática y de tecnología lo más amplia posible (art. 1.2). Pero, a diferencia del Convenio de Aarhus y de la Directiva 2003/4/CEE, sitúa en primer lugar la faceta activa con el claro propósito de reforzarla a fin de que una amplia publicidad activa de fácil accesibilidad se convierta en la base sobre la que se asienta el acceso a la información ambiental ${ }^{37}$.

La difusión de la información por las autoridades públicas (capítulo II del título II, arts. 6-9, LIPPJMA) es una obligación que abarca a todas las autoridades públicas $\mathrm{y}$, por lo tanto, también a los sujetos privados integrados en esa noción ${ }^{38}$, si bien, a la vista de su contenido, se refiere primordialmente a las Administraciones públicas. $\mathrm{Y}$, además, debe sujetarse a determinadas exigencias específicas a fin de facilitar la difusión y la accesibilidad: una divulgación lo más amplia y sistemática posible (art. 6.1), que ha de desarrollarse mediante la organización y actualización de la información ambiental para su difusión activa y sistemática al público por medios electrónicos y la creación de bases de datos electrónicas o de enlaces con direcciones electrónicas a través de las cuales pueda accederse a dicha información (art. 6.2, 3 y 4 LIPPJMA).

actividad y las medidas correctoras para evitar ruidos constituye información urbanística y ambiental (Sugerencia del Defensor del Pueblo de 13 de junio de 2016, queja núm. 15011195).

${ }^{36}$ En razón de la acción pública establecida por la legislación urbanística (Sugerencia del Defensor del Pueblo de 24 de julio de 2017, queja núm. 15007051).

${ }^{37}$ Al papel de la vertiente activa y su diferencia con la pasiva se refiere la STS de 4 de abril de 2006 (recurso de casación núm. 311/2003). Véanse RAZQUIN LIZARRAGA y RUIZ DE APODACA ESPINOSA, Información... cit., pp. 180-203; y VARGA PASTOR, A. de la y FUENTES I GASÓ, J. R., "Las autoridades públicas ante las nuevas obligaciones en materia de información ambiental. Especial referencia a la difusión de información ambiental", PIGRAU SOLÉ (dir.), Acceso a la información... cit., pp. 117-224.

${ }^{38}$ Se prevé la celebración de convenios de colaboración entre la Administración General del Estado y el sector empresarial y otras organizaciones para establecer puntos de información digitalizada (disposición adicional séptima LIPPJMA), así como la difusión periódica de información ambiental por operadores económicos cuando no estén obligados a ello respecto de sus actividades o productos que tengan o puedan tener efectos significativos sobre el medio ambiente (disposición adicional duodécima LIPPJMA). 
El contenido mínimo de la difusión comprende las normas ambientales ampliada a la jurisprudencia para la Administración General del Estado en virtud del artículo 6.5-, las políticas, los programas y los planes relativos al medio ambiente, junto con sus evaluaciones ambientales, los informes sobre el estado del medio ambiente (a los que se refiere el artículo 8), los datos o resúmenes del seguimiento de actividades que afecten o puedan afectar al medio ambiente, las autorizaciones con efecto significativo sobre el medio ambiente y los acuerdos en materia de medio ambiente y los estudios de impacto ambiental y de evaluación de riesgo (art. 7 LIPPJMA). Y, por su especial relevancia, se recoge específicamente la difusión de información en caso de amenaza inminente para la salud humana o para el medio ambiente ocasionada por actividades humanas o por causas naturales, que deberá ser inmediata y sin demora para permitir al público adoptar las medidas necesarias para prevenir o limitar los daños que pudieran derivarse de dicha amenaza (art. 9 LIPPJMA). A ello se añade la difusión periódica de las estadísticas sobre las solicitudes de información recibidas y sobre la experiencia adquirida en la aplicación de la Ley, garantizando en todo caso la confidencialidad de las personas (disposición adicional octava LIPPJMA) ${ }^{39}$.

Esta vertiente ha evolucionado de forma notable. La publicidad activa de información ambiental tiene un contenido amplio que es satisfecho a través de las páginas web de las Administraciones ambientales ${ }^{40}$. Asimismo, otras normas ambientales específicas establecen registros o listas de información ambiental [art. 5.3.c) LIPPJMA]: el Registro Estatal de Emisiones y Fuentes Contaminantes (PRTR-España) $)^{41}$; el Registro Nacional de Derechos de

\footnotetext{
39 Los informes estadísticos anuales están publicados en www.mapama.gob.es/es/.../informacion/informacion-ambiental/informes-estadisticos/ (Última consulta, 23 de abril de 2018).

${ }^{40}$ Al cumplimiento de las obligaciones específicas de difusión se refiere el Informe estadístico 2016 sobre acceso a la información ambiental, pp. 31-94, del Ministerio de Agricultura y Pesca, Alimentación y Medio Ambiente (www.mapama.gob.es/es/.../informacion/informacionambiental/informes-estadisticos/ [Última consulta, 23 de abril de 2018]).

${ }^{41}$ En este registro se pone a disposición del público información sobre las emisiones a la atmósfera, al agua y al suelo de las sustancias contaminantes y datos de transferencias de residuos de las principales industrias y otras fuentes puntuales y difusas, de acuerdo con la legislación internacional (Protocolo de Kiev y Convenio de Aarhus), europea (Reglamento EPRTR) e interna (Real Decreto Legislativo 1/2016, de 16 de diciembre, por el que se aprueba el texto refundido de la Ley de prevención y control integrados de la contaminación, y Real Decreto 508/2007, de 20 de abril).
} 
Emisión ${ }^{42}$; el Registro de Aguas ${ }^{43}$; el Sistema Básico de Información sobre la Contaminación Acústica (SICA $)^{44}$; la información sobre calidad del aire y el Sistema Español de Información, Vigilancia y Prevención de la Contaminación Atmosférica45; el Sistema de Información Nacional de Aguas de Baño (NÁYADE)46; el Inventario Español del Patrimonio Natural y de la Biodiversidad $^{47}$; y la información al público en relación con el control de accidentes graves en los que intervengan sustancias peligrosas ${ }^{48}$. Asimismo, también han de destacarse los sistemas de información espacial ${ }^{49}$.

No obstante, se aprecian algunas deficiencias y dificultades. En primer lugar, la rápida y fácil accesibilidad se ve dificultada por la dispersión en los puntos de información dentro de cada Administración pública, que aparece compartimentalizada o segmentada por referencia a distintos temas o categorías de actividad, sin que exista ninguna plataforma o portal general de información ambiental.

\footnotetext{
42 Los registros nacionales de derechos de emisión de los países miembros de la Unión Europea se encuentran integrados, junto con el Registro de la Unión, en una plataforma común (gestionada por la Comisión Europea) denominada Sistema Consolidado de Registros de la Unión Europea (CSEUR). Ley $1 / 2005$, de 9 de marzo, por la que se regula el régimen del comercio de derechos de emisión de gases de efecto invernadero; Real Decreto 1264/2005, de 21 de octubre, por el que se regula la organización y funcionamiento del Registro nacional de derechos de emisión; y Reglamento (UE) núm. 389/2013 de la Comisión, de 2 de mayo, por el que se establece el Registro de la Unión de conformidad con la Directiva 2003/87/CE.

${ }^{43}$ Artículos 80 TRLA y 189-195 del Reglamento del Dominio Público Hidráulico, aprobado por Real Decreto 849/1986, de 11 de abril (modificado por Real Decreto 670/2013, de 6 de septiembre).

44 Artículo 5 de la Ley 37/2003, de 17 de noviembre, del Ruido, y, en su desarrollo, artículo 4 y disposición adicional única del Real Decreto 1513/2005, de 16 de diciembre.

${ }^{45}$ Artículos 8 y 29 de la Ley 34/2007, de 15 de noviembre, de calidad del aire y protección de la atmósfera.

${ }^{46}$ Real Decreto 1341/2007, de 11 de octubre, sobre la gestión de la calidad de las aguas de baño.

47 Artículo 9 Ley 42/2007, de 13 de diciembre, del Patrimonio Natural y de la Biodiversidad; y Real Decreto 556/2011, de 20 de abril, para el desarrollo del Inventario Español del Patrimonio Natural y la Biodiversidad.

${ }^{48}$ Se trata de la normativa Seveso, hoy Directiva 2012/18/UE del Parlamento Europeo y del Consejo, de 4 de julio de 2012 (Directiva Seveso III), incorporada por el Real Decreto $840 / 2015$, de 21 de septiembre, por el que se aprueban medidas de control de los riesgos inherentes a los accidentes graves en los que intervengan sustancias peligrosas.

${ }^{49}$ La Directiva Inspire (Directiva 2007/2/CE) y el Programa Copernicus [Reglamento (UE) núm. 377/2014]. Y la Ley 14/2010, de 5 de julio, sobre las infraestructuras y los servicios de información geográfica en España, que prevé la disposición de datos a través del Geoportal de la Infraestructura de Datos Espaciales de España (art. 5). Véase RAMS RAMOS, L., "El acceso a los sistemas de información geográfica y su reutilización", Valero Torrijos, J. y Fernández Salmerón, M. (coords.), Régimen jurídico de la transparencia del sector público: del Derecho de acceso a la reutilización de la información, Aranzadi, Cizur Menor, 2014, pp. 587-629.
} 
En segundo lugar, la información debe ser de calidad -término de la Directiva que no se recoge en la LIPPJMA—, esto es, ha de ser actualizada, precisa y susceptible de comparación ${ }^{50}$, propiciándose una coordinación de criterios sobre la presentación de esa publicidad entre las distintas Administraciones públicas con base en el principio de colaboración (art. 4 LIPPJMA) a fin de hacer realidad la interoperabilidad ${ }^{51}$ y facilitar su adecuada utilización posterior por el público ${ }^{52}$.

En tercer lugar, la información en caso de amenaza inminente para la salud humana o el medio ambiente debería diferenciarse, más que por razón de sexo —como apunta el artículo 9.1 LIPPJMA—, en atención a los distintos grupos de riesgo.

Finalmente, la creciente sensibilización ambiental del público exige ampliar el campo de la información difundida, incluyendo toda la información relevante 53 $y$, en concreto, la información por los operadores económicos de actividades o productos con posibles efectos significativos sobre el medio ambiente (disposición transitoria duodécima LIPPJMA) ${ }^{54}$. El principio de precaución impone una especial obligación informativa respecto de aquellos productos que puedan tener una significativa afectación general sobre el medio ambiente, más allá de las exigencias de etiquetado, mediante la difusión de tal información ambiental por parte de las autoridades públicas, en particular,

${ }^{50}$ En este sentido, la Sugerencia del Defensor del Pueblo de 20 de septiembre de 2016 (queja 14022784) de poner a disposición del público, gratuitamente, los datos históricos sobre precipitaciones diarias en un punto concreto en España que obren en poder de la Agencia Española de Meteorología conforme al artículo 6 LIPPJMA.

51 El Informe de cumplimiento presentado por España a la Reunión de las Partes del Convenio de Aarhus de 28 de noviembre de 2016 reconoce que no se ha logrado la interoperabilidad.

${ }^{52}$ Así se aprecia la diversidad de la información estadística periódica sobre las solicitudes de información ambiental presentadas ante las Administraciones públicas.

${ }^{53}$ Así el Defensor del Pueblo se refiere a la negativa de la Secretaría de Estado de Medio Ambiente de divulgar la información relativa al empleo de la fractura hidráulica en la exploración, investigación y explotación de hidrocarburos (Informe anual 2015, p. 552).

54 El Reglamento (CE) núm. 1221/2009 del Parlamento Europeo y del Consejo de 25 de noviembre de 2009, relativo a la participación voluntaria de organizaciones en un sistema comunitario de gestión y auditoría medioambientales (EMAS) (objeto de ulteriores modificaciones), impone a las empresas que obtienen esta certificación obligaciones de información pública sobre el cumplimiento de los requisitos legales que les son aplicables en materia de medio ambiente y sobre su comportamiento medioambiental. Véase RUIZ DE APODACA ESPINOSA, Á. M., "Transparencia empresarial e información ambiental", Sanz Larruga, J. (dir.) y otros, Libre mercado y protección ambiental: intervención y orientación ambiental de las actividades económicas, INAP, Madrid, 2013, pp. 387-419. 
las Administraciones públicas que conocen tales cuestiones en los procesos autorizatorios de su competencia.

\section{EL DERECHO DE ACCESO A LA INFORMACIÓN AMBIENTAL MEDIANTE SOLICITUD}

La faceta pasiva se manifiesta en el derecho a acceder a la información ambiental que obre en poder de las autoridades públicas o en el de otros sujetos que la posean en su nombre [arts. 1.1.a) y 3.1 LIPPJMA], que se regula en el capítulo III del título II (arts. 10-12 LIPPJMA), complementado por las limitaciones al acceso (capítulo IV del título II, arts. 13-14 LIPPJMA) y los ingresos de derecho público y privado (art. 15 LIPPJMA) ${ }^{55}$.

\section{Configuración como un derecho legal específico}

El acceso a la información ambiental mediante solicitud se configura como un derecho (art. 1 y 3.1 LIPPJMA), con el correlativo deber de las autoridades públicas de suministrar la información solicitada ${ }^{56}$.

El titular del derecho es el público o toda persona, cualquiera que sea su nacionalidad, domicilio o sede y sin que esté obligada a declarar un interés determinado [art. 3.1.a) LIPPJMA], esto es, un concepto general e indiscriminado, distinto y más amplio que las nociones de "público interesado" o "persona interesada" e incluso ciudadano, que comprende a todos sin distinción ni exigencia de justificación, incluyendo a las entidades locales ${ }^{57}$. Por lo tanto,

\footnotetext{
55 Véanse RAZQUIN LIZARRAGA y RUIZ DE APODACA ESPINOSA, Información... cit., pp. 204-272; y CASADO CASADO, L., "El derecho de acceso a la información ambiental previa solicitud", Pigrau Solé (dir.), Acceso a la información... cit., pp. 225-298.

56 Como señala la STSJ Canarias (Las Palmas) 175/2012, de 23 de noviembre (recurso contencioso-administrativo núm. 225/2011), la Administración tiene una obligación de suministro, salvo excepciones, por lo que no cabe la inactividad. $Y$ en el mismo sentido, la STSJ Canarias (Las Palmas) 198/2012, de 21 de diciembre (recurso contencioso-administrativo núm. 389/2010), ordena que se facilite la información sobre la actividad que se desarrolla en una central de energía eléctrica y si tal actividad está amparada por las oportunas licencias exigibles o, en caso contrario, comunicar al solicitante los motivos de la negativa a facilitarla.

${ }^{57}$ A esta definición se refiere el apartado segundo de la Orden AAA/1601/2012, que señala que la jurisprudencia ha reconocido expresamente este derecho a las Administraciones públicas, en concreto, a los entes locales (sentencias del TSJ de Cataluña de 19 de abril de 2000 y del TSJ de Madrid de 3 de octubre de 2006). Esta inclusión de los entes locales se aprecia en la Resolución del Defensor del Pueblo de España de 30 de marzo de 2017.
} 
es un derecho universal, tanto individual como colectivo, sin discriminación alguna.

El público, una vez formulada la petición de información, se convierte en solicitante, adquiriendo la condición de interesado en el procedimiento de acceso a la información (art. 2.6 LIPPJMA).

Los obligados son las autoridades públicas en sentido amplio (art. 2.4), más allá de las Administraciones públicas y entes del sector público, incluyendo sujetos privados (art. 2.4.2), cuyo deber de suministro puede exigir la obligación positiva de disponer de la información exigible en ejercicio de sus competencias que pueda ser solicitada por el público ${ }^{58}$.

El derecho de acceso a la información ambiental se caracteriza por tres aspectos. En primer lugar, es un derecho legal, y no fundamental ${ }^{59}$, que confiere un estatus público subjetivo que se puede hacer valer ante las autoridades públicas y los órganos judiciales en los términos fijados en esta ley y ha de ejercerse de acuerdo con la buena fe y sin abuso de derecho (inciso inicial artículo 3 LIPPJMA). En segundo lugar, tiene carácter material y no formal, pues consiste en la obtención de la información solicitada, esto es, en el suministro de la información más que en la resolución de la solicitud ${ }^{60}$. Su imprescindible efectividad requiere una configuración práctica, por lo que se integra por un conjunto de garantías o haz de derechos que permitan su ejercicio real y efectivo: la información sobre dicho derecho y el asesoramiento para su correcto ejercicio; la asistencia en la búsqueda de información; el suministro en los plazos legales; la recepción de la información en el formato elegido; la motivación de las decisiones que deniegan, total o parcialmente, el acceso o no facilitan la información en la forma solicitada; y la información

\footnotetext{
${ }^{58}$ En este sentido, son reiteradas las sugerencias del Defensor del Pueblo que se refieren al desarrollo de actuaciones de inspección, medición o supervisión por las Administraciones públicas a fin de facilitar al público la información ambiental solicitada. Así, las sugerencias de 6 de mayo de 2016 sobre zona acústicamente saturada (queja 15012737) y de 26 de agosto de 2016 sobre contaminación acústica de la base aérea de Zaragoza (queja 15011680).

${ }^{59}$ STS de 14 de febrero de 2011 (recurso de casación núm. 2053/2008).

${ }^{60}$ Como señala Schmidt-Assmann, los procedimientos administrativos no han de concluir por definición en una resolución jurídica de carácter formal, son muchas las actuaciones que no desembocan en una decisión formalizada. SCHMIDT-ASSMANN, E., "Pluralidad de estructuras y funciones de los procedimientos administrativos en el Derecho alemán, europeo e internacional", Barnés, J. (ed.), La transformación del procedimiento administrativo, Editorial Derecho Global, Sevilla, 2008, p. 75.
} 
sobre el listado de tasas y precios en su caso exigibles y de las exenciones o dispensas de pago [art. 3.1.b) a g) LIPPJMA]. Y, en tercer lugar, es un derecho básico, mínimo y transversal, que se superpone o adiciona a cualquier otro derecho reconocido en la Constitución o las leyes (art. 3.4 LIPPJMA) $^{61}$ y se irradia a todas las cuestiones ambientales, por lo que debe ser respetado por toda la legislación ambiental estatal y autonómica.

El derecho de acceso a la información ambiental juega de forma independiente y también en conexión con los procedimientos administrativos. Puede ejercitarse antes, durante y después de cualquier procedimiento en el que el público quiera participar62. Por otro lado, el derecho a conocer constituye el presupuesto indispensable o primera garantía del derecho de participación pública [art. 3.2.b) y 16.1.a) LIPPJMA] ${ }^{63}$, y el público interesado goza de una posición reforzada para la obtención de la información adecuada y suficiente en los procedimientos administrativos ${ }^{64}$.

\section{Procedimiento}

61 Como muestra la Sugerencia del Defensor del Pueblo de 21 de marzo de 2016, sobre acceso a información urbanística (queja 14019017), la petición de información ambiental puede fundarse simultáneamente en varias normas (LIPPJMA, legislación urbanística y LTAIBG). Por ello, sorprende la STSJ Canarias (Las Palmas) 46/2017, de 20 de febrero (recurso contencioso-administrativo núm. 136/2016), que confirma la denegación del acceso a la información ambiental formulada por una asociación ecologista ante un ayuntamiento en relación con un expediente tramitado por la Comunidad Autónoma, por considerar que la petición que se formula no lo es sobre el estado de tramitación de un procedimiento, sino que se plantea como la respuesta a una serie de preguntas como si de un examen se tratara, y esta forma de obtener información no está amparada en disposición alguna, sino que, en todo caso, debió acudirse a lo dispuesto en la Ley 27/2006.

62 En este sentido, véase la Resolución de 30 de marzo de 2016 del Defensor del Pueblo de España. Asimismo, la STSJ de Galicia (A Coruña) 600/2017, de 22 de noviembre (recurso contencioso-administrativo núm. 7363/2015), si bien con referencia a la normativa anterior ya derogada (Ley 38/1995 y Directiva 90/313/CEE).

${ }_{63}$ Así lo explicita el artículo 6.3.c) de la Directiva 2011/92/UE del Parlamento Europeo y del Consejo, de 13 de diciembre de 2011, relativa a la evaluación de las repercusiones de determinados proyectos públicos y privados sobre el medio ambiente. Por otro lado, de acuerdo con el apartado 1 de la disposición adicional primera LTAIBG, la normativa reguladora del correspondiente procedimiento administrativo será la aplicable al acceso a los documentos que se integren en un procedimiento administrativo en curso por parte de quienes tengan la condición de interesados en este. En este sentido, la STS de 21 de abril de 2010 (recurso de casación núm. 7523/2005) analiza la queja de insuficiente información ambiental en un procedimiento relativo a un estudio de información y evaluación ambiental de carretera.

${ }^{64}$ El Defensor del Pueblo alude a la especial posición del interesado (Recordatorio de 11 de noviembre de 2015, queja 14024146) y a esa mayor amplitud (Recordatorio de 30 de mayo de 2017, queja 13026497). Y la STSJ País Vasco 682/2012, de 12 de diciembre (recurso núm. 1088/2010), entiende que el acceso a la información está embebido en el de participación pública. 
La configuración material, más que formal, del derecho de acceso a la información se manifiesta en la regulación incompleta del procedimiento (capítulo III del título II, arts. 10-12 LIPPJMA), que se limita a fijar unas reglas básicas o mínimas centradas en la presentación de solicitudes, plazo de resolución y forma de suministro de la información, con escasa atención a la tramitación.

El procedimiento comienza con la petición presentada por cualquier persona en demanda del suministro de información ambiental. La solicitud no está sujeta a formalidad alguna, por lo que basta con indicar la identificación del solicitante y de la autoridad competente, así como la información ambiental que se pretende obtener, sin obligación de declarar interés o justificación alguna [art. 3.1.a) LIPPJMA], pero sí puede especificarse el formato o la forma de facilitar la información solicitada y requerirse el método utilizado en la obtención de la información (art. 12 LIPPJMA), así como el calendario para su suministro. La solicitud ha de dirigirse a la autoridad pública competente, entendiendo por tal aquella que dispone de la información ambiental (art. 10.1 LIPPJMA), pero puede presentarse en cualquiera de los lugares previstos en la legislación general del procedimiento administrativo común, si bien el plazo para contestar no se iniciará hasta la entrada de la petición en el registro del órgano competente [art. 10.2.c). $1^{\circ}$ LIPPJMA]. La solicitud puede formularse a través de los distintos medios autorizados por el ordenamiento jurídico, preferentemente por medios electrónicos tanto por la gradual implantación de la Administración electrónica como por la exención de contraprestación económica para la información suministrada electrónicamente ${ }^{65}$. Pese a esa simplicidad de la solicitud de información ambiental, se prevé - a modo de excepciones - la posible subsanación de defectos, ya que no cabe el rechazo o inadmisión directa de las peticiones que incumplan las exigencias legales [art. 10.2.a) LIPPJMA].

La cuestión clave es el plazo que se tarda en suministrar la información solicitada, que parte del inexcusable deber de las autoridades públicas de

${ }^{65}$ Los medios de acceso mayoritarios en el MAPAMA son el teléfono y el correo electrónico, según resulta del Informe estadístico 2016 sobre acceso a la información ambiental, pp. 31-94, del Ministerio de Agricultura y Pesca, Alimentación y Medio Ambiente (www.mapama.gob.es/es/ministerio/servicios/informacion/informacion-ambiental/informesestadisticos/ [Última consulta, 23 de abril de 2018]). 
facilitar la información ambiental pedida, salvo que concurra una causa legal que lo impida66. El principio de agilidad [art. 5.1.f) LIPPJMA] impone la brevedad de los plazos de suministro67: la información ambiental ha de ser facilitada lo antes posible y, en todo caso, en el plazo máximo de un mes, que podrá, excepcionalmente, ampliarse a dos meses por razones de volumen o complejidad de la información solicitada que impidan cumplir el plazo general y previa información de la ampliación al solicitante [art. 10.2.c) LIPPJMA].

La experiencia muestra problemas en la satisfacción de estas exigencias: por una parte, a veces se confunde la resolución de la solicitud con el suministro de la información, cuando en realidad tales plazos se refieren a la obtención de la información por el solicitante [art. 3.1.b) LIPPJMA]; y, por otra, se incumplen tales plazos máximos para facilitar la información pedida, sin contemplarse el silencio administrativo en caso de falta de suministro en plazo ${ }^{68}$, lo que ha sido colmado por la jurisprudencia, que, en aplicación de las reglas del procedimiento administrativo común, entiende que, en caso de falta de respuesta en plazo, entra en juego el silencio administrativo positivo, por lo que la solicitud debe entenderse estimada ${ }^{69}$.

Ahora bien, la estimación de la solicitud por silencio, pese a su condición a todos los efectos de acto finalizador del procedimiento que no puede ser ignorado por una resolución posterior [art. 24.2 y 3.a) LPACAP], plantea varias cuestiones $^{70}$ : en primer lugar, el difícil encaje de la figura del silencio con la configuración material del derecho de acceso, que exige, bien el suministro de la información ambiental, bien la denegación motivada en plazo ${ }^{71}$; en segundo

66 Como señalan las sugerencias del Defensor del Pueblo de 6 de mayo de 2016 (queja 15012737) y de 18 de agosto de 2017 (queja 17007078).

67 Se exige una celeridad procedimental y coordinación entre unidades, como indica el apartado tercero de la Orden AAA/1601/2012.

${ }^{68} \mathrm{~A}$ diferencia de la Ley 38/1995, que preveía inicialmente el silencio negativo (art. 4.1), luego suprimido por su reforma por la Ley 55/1999.

69 Por todas, STS de 16 de enero de 2015 (recurso de casación núm. 691/2013) y STSJ Comunidad de Madrid 365/2016, de 16 de junio (procedimiento ordinario 134/2015).

70 Son muestra de la aporía del silencio administrativo a que se ha referido PAREJO ALFONSO, L., "El silencio administrativo, especialmente el de sentido estimatorio, como aporía. Apuntes de una posible vía de superación", Parejo Alfonso, L., El silencio en la actividad de la Administración pública, Tirant lo Blanch, Valencia, 2011, pp. 11-32.

71 Según la STJUE de 21 de abril de 2005 (C-186/04, Housieaux), bajo la Directiva de 1990, el silencio dentro del plazo imperativo pudiera considerarse como una denegación presunta que puede ser objeto de impugnación, si bien se infringe la exigencia de motivación. Asimismo, el Comité de Cumplimiento del Convenio de Aarhus entiende que el silencio positivo es contrario al Convenio. Véase MARTíNEZ GUTIÉRREZ, R., "El silencio administrativo en el acceso a la 
lugar, la materialización del suministro, ya que el objetivo de la solicitud es, como se viene insistiendo, no la resolución del procedimiento, sino la obtención de la información solicitada, por lo que, dando un paso más, podría entenderse viable, en caso de silencio positivo, la exigencia del suministro a través del cumplimiento de la obligación de realizar una prestación a favor del solicitante (cfr. art. 29.1 LJCA) ${ }^{72}$; y, finalmente, la posición, en su caso, de terceros que estén protegidos por algunas de las limitaciones a la divulgación de la información.

\section{Forma o formato de la información}

La forma o formato del suministro tiene relevancia práctica en razón del carácter finalista e instrumental de este derecho y la posible utilización posterior de la información obtenida. El solicitante tiene derecho a que la información le sea suministrada en la forma o soporte indicados en la solicitud [art. 3.1.e) LIPPJMA], salvo dos excepciones: cuando se trate de información ya difundida en un determinado formato de fácil acceso para el solicitante o si la autoridad pública considera razonable facilitar la información en otro formato de manera justificada (art. 11 LIPPJMA) ${ }^{73}$. Asimismo, el solicitante tiene derecho a que se

información ambiental (Comentario a la STJCE de 21 de abril de 2005, asunto C-.186-04)", Revista Aranzadi de Derecho Ambiental, núm. 9, 2006, pp. 163-175. Como indica Cubero Marcos, la LIPPJMA no pretende regular el silencio, sino que únicamente impone dos deberes: el de entregar la información en un plazo y el de motivar la decisión si se deniega el acceso. CUBERO MARCOS, J. I., "El derecho de acceso a la información ambiental y su adaptación a la normativa general sobre transparencia administrativa: algunos casos controvertidos", Revista Aranzadi de Derecho Ambiental, núm. 37, 2017, p. 143.

72 Como declara la STSJ Comunidad Valenciana 649/2012, de 5 de diciembre (recurso contencioso-administrativo núm. 824/2010).

${ }^{73}$ De acuerdo con el apartado cuarto ("Forma o formato de la información suministrada") de la Orden AAA/1601/2012, la segunda excepción puede justificarse alegando imposibilidad material, costes desproporcionados para el cumplimiento de la petición en el soporte indicado o exigencias técnicas, como soportes obsoletos, poco extendidos o no disponibles en la Administración suministradora. Además, tras recordar la preferencia por los medios electrónicos, en los casos en los que la información sea entregada en formato papel, deberá utilizarse un papel reciclado y libre de cloro en su totalidad y la impresión deberá realizarse a doble cara. Y, finalmente, por regla general, no se habrá de tratar la información para ajustarse a la solicitud, por lo que, cuando se soliciten ciertos datos desagregados en relación con determinados parámetros, se podrá proceder en dicho sentido en tanto en cuanto se disponga de herramientas a tal efecto y datos suficientes para proceder de modo sencillo; en caso contrario, se entregarán al máximo nivel de desagregación que sea posible dado el estado de la tecnología de la que disponga la unidad y la estructuración de los datos que obren en su poder. $Y$ en los casos en que se solicite un tratamiento de la información concreto, se entregará en su lugar la información de referencia en el estado en que obre en poder de la Administración para que, a partir de esta, el interesado, en su caso, procese dichos datos. 
le informe sobre el método utilizado en la obtención de la información, si está disponible, por referencia al lugar donde puede encontrar información sobre el método de medición y el procedimiento normalizado empleado (art. 12 LIPPJMA).

\section{Contraprestación económica}

La LIPPJMA autoriza el cobro por las autoridades públicas de una contraprestación económica por el suministro de información, estableciendo la obligación de elaborar, publicar y poner a disposición de los solicitantes la información del listado de tasas y precios públicos y privados que sean de aplicación a las solicitudes, así como los supuestos en que no proceda pago alguno [arts. 3.1.g) y 15.1 LIPPJMA]. Además, determina la gratuidad del acceso a las listas o registros de autoridades ambientales y de información ambiental y el examen in situ de la información solicitada (art. 15.1 LIPPJMA). $\mathrm{Y}$, respecto de la Administración General del Estado y sus organismos públicos, regula la tasa por suministro de información ambiental, fijando criterios para su cuantificación y exenciones objetivas para las entregas de menos de veinte páginas en formato DIN A4 y el envío de información por vía telemática (disposición adicional primera LIPPJMA) ${ }^{74}$.

Pese al silencio legal, la posible contraprestación económica por el suministro de información está sujeta a dos reglas generales: por una parte, su presupuesto es el suministro de la información solicitada, por lo que no puede exigirse en caso de denegación; y, por otra, su cuantía ha de ser razonable -

\footnotetext{
${ }^{74}$ El apartado quinto de la Orden AAA/1601/2012 se refiere al régimen de contraprestación por el derecho a la información ambiental. Por Orden PRE/1597/2014, de 5 de septiembre, se establecen las cuantías y se dictan normas sobre la gestión y el cobro de la tasa por suministro de información ambiental en el ámbito de la Administración General del Estado y sus organismos públicos. La STSJ de Aragón 324/2017, de 20 de septiembre (recurso contenciosoadministrativo núm. 287/2016), estima el recurso promovido por una asociación ecologista contra la tasa exigida por suministro de información, por entender que la Orden citada no prevé una tasa específica de escaneado, sino únicamente una tasa por los soportes físicos en los que se remite la información digitalizada, y a la actora no se le han entregado fotocopias de ninguna de estas clases, esto es, la reproducción de las imágenes no se ha hecho "sobre papel u otro material" - RAE- tamaños DIN A3 o DIN A4, sino en soporte digital, lo que comporta claramente un menor coste para la Administración.
} 
como dispone el artículo 4.8 Convenio de Aarhus ${ }^{75}$ - a fin de que no sea un obstáculo o disuasión al ejercicio del derecho.

En la práctica se han producido algunas exigencias económicas abusivas o irrazonables ${ }^{76}$. El actual estado de implantación de la Administración electrónica debe conllevar que la regla sea la gratuidad, ya que la exigencia del pago está ligada al coste de los materiales utilizados y del envío.

\section{Límites al acceso a la información ambiental}

El derecho de acceso a la información ambiental no es un derecho absoluto, sino que está limitado por las excepciones legalmente establecidas en línea con el Convenio de Aarhus y la Directiva (art. 13-14 LIPPJMA) $^{77}$, que son también aplicables a la faceta activa (art. 13.3 LIPPJMA).

\section{a) Primera lista de excepciones: circunstancias procedimentales}

La primera lista de excepciones pretende preservar el correcto funcionamiento de la autoridad competente. Se trata — con la salvedad de la última- de circunstancias formales o procedimentales que no motivan propiamente la denegación del acceso, sino más bien una suerte de inadmisión conectada con las exigencias de la solicitud de información ambiental, por lo que cabe su

\footnotetext{
75 Según la STJUE de 6 de octubre de 2015 (C-71/14, East Sussex County Council), la contraprestación económica impuesta por el suministro de un tipo concreto de información medioambiental no puede incluir parte alguna de los gastos generados por el mantenimiento de una base de datos, utilizada al efecto por la autoridad pública, pero sí puede incluir los gastos generales imputables al tiempo dedicado por el personal de dicha autoridad a responder a solicitudes de información individuales, debidamente computados en la determinación de dicha contraprestación económica, siempre que el importe global de esta última no exceda de lo razonable.

${ }^{76}$ Así, la decisión V/9k sobre cumplimiento por España, adoptada en la Reunión de las Partes del Convenio de Aarhus, Maastricht, Holanda, 20 de junio y 1 de julio de 2014, se refiere a tasas exigidas por el Ayuntamiento de Murcia por copias de información ambiental (ECE/MP.PP/2014/2/ADD.1). Y ante el Defensor del Pueblo se ha planteado el caso de los precios que cobra la Agencia Estatal de Meteorología por la información que proporciona (Informe anual 2015, p. 551). Véase PELÁEZ MURAS, M., "El acceso a la información ambiental en poder de la Administración regional: Seis notas prácticas y una dificultad superada en parte", Gabilex: Revista del Gabinete Jurídico de Castilla-La Mancha, núm. 8, 2016, pp. 40-81, que se refiere a la tasa exigida en la Comunidad Autónoma de Castilla-La Mancha.

${ }^{77}$ El apartado sexto ("Excepciones a la obligación de facilitar la información ambiental") y el anexo ("Aclaraciones y criterios jurisprudenciales relativos a las excepciones a la obligación de facilitar información ambiental") de la Orden AAA/1601/2012 fijan criterios para su aplicación.
} 
reformulación o reiteración en términos adecuados. Estas excepciones son las siguientes (art. 13.1 LIPPJMA):

i) La falta de disponibilidad de la información por no obrar en poder de la autoridad a la que se ha solicitado o de otra autoridad en su nombre. No se contempla, a diferencia de otras regulaciones, la denominada "regla de autor", ya que la disponibilidad se refiere a la información poseída y que haya sido recibida o elaborada por la autoridad pública (art. 2.4 LIPPJMA), por lo que no cabe denegar el acceso alegando que la información ha sido elaborada por otra autoridad o por un particular ${ }^{78}$.

La indisponibilidad concurre en dos supuestos. Por una parte, cuando no existe la información solicitada ${ }^{79} \sin$ que la autoridad pública deba reelaborar la información poseída; pero ello no puede derivar del incumplimiento de otras obligaciones (supervisión o inspección de actividades ambientales), por lo que, como se ha indicado, deberá desarrollar las actuaciones necesarias a fin de suministrar la información requerida. Y, por otra, cuando la información existe pero no está en poder de la autoridad pública a la que se ha solicitado, si bien en tal caso debe remitir la solicitud a la autoridad que la posea - de lo cual se debe informar al solicitante- $y$, cuando ello no sea posible, deberá informarle de la autoridad pública a la que, según su conocimiento, ha de dirigirse para solicitar la información [art. 10.2.b) LIPPJMA].

Esta excepción debería tener escasa o nula efectividad en vista de los listados de autoridades competentes de obligada difusión [art. 5.1.c) LIPPJMA] y no es aplicable cuando se haya remitido el expediente a un órgano judicial ${ }^{80}$. En todo

\footnotetext{
${ }^{78}$ No obstante, la STS de 11 de julio de 2014 (recurso de casación núm. 1296/2012) entiende que, al derecho de acceso a documentación remitida a un expediente por órganos comunitarios (dictamen motivado de la Comisión), resultan de preferente aplicación la normativa europea contenida en el Reglamento CE 1049/2001, sobre la legislación interna, y, en especial, la Ley 27/2006, con el consiguiente deber de solicitar previamente al órgano emisor del dictamen el derecho o no al acceso.

79 STSJ Aragón 160/2008, de 11 de marzo (recursos contencioso-administrativos núms. 317/04-A y 45/05-B); y STSJ Principado de Asturias 1267/2011, de 27 de noviembre (recurso contencioso-administrativo núm. 1106/2009).

${ }^{80}$ En contra de lo expuesto, el apartado B). $3^{\circ}$ del anexo de la Orden AAA/1601/2012 señala que, en caso de que el expediente no obrara en poder de la unidad por haberse remitido al órgano jurisdiccional competente, la solicitud se habrá de denegar sobre la base del artículo 13.1.a), al no disponer en su poder de dicha información. Ahora bien, tal criterio parece erróneo, ya que la Administración continúa disponiendo de la información, hasta el punto de que puede continuar con la ejecución de la actuación administrativa correspondiente a ese expediente pese a la impugnación en sede judicial.
} 
caso, la regla general debe ser el reenvío a la autoridad pública competente, no la denegación ${ }^{81}$.

ii) El carácter manifiestamente irrazonable de la solicitud, derivado de la obligación de ejercer el derecho de acuerdo con la buena fe y sin abuso de derecho (inciso inicial del artículo 3 LIPPJMA), que no puede confundirse con el volumen o complejidad de la información solicitada, circunstancia que puede motivar la ampliación del plazo para facilitar la información. Por tanto, la irrazonabilidad ha de ser manifiesta y se identifica con el ejercicio abusivo del derecho ${ }^{82}$.

iii) La formulación de la solicitud en términos demasiado generales, esto es, de manera imprecisa por no determinar debidamente la concreta información ambiental solicitada, se refiere a las solicitudes cuya generalidad impida la cabal identificación de su objeto por la autoridad pública ${ }^{83}$. Esta excepción no puede aplicarse de forma automática, ya que la autoridad pública debe requerir y asistir al solicitante para que concrete su petición de información antes de que expire el plazo ordinario de un mes [art. 10.2.a) LIPPJMA].

iv) La solicitud referida a material en curso de elaboración o a documentos o datos inconclusos. En razón de la abusiva interpretación de esta limitación en la normativa precedente, corregida por la jurisprudencia ${ }^{84}$, se han introducido

81 Por ello, sorprende la STSJ Canarias (Las Palmas) 46/2017, de 20 de febrero (recurso contencioso-administrativo núm. 136/2016), que confirma la denegación del acceso a la información ambiental formulada por una asociación ecologista ante un ayuntamiento en relación con un expediente tramitado por la Comunidad Autónoma, por considerar que la petición que se formula no lo es sobre el estado de tramitación de un procedimiento, sino que se plantea como la respuesta a una serie de preguntas como si de un examen se tratara, y esta forma de obtener información no está amparada en disposición alguna, sino que, en todo caso, debió acudirse a lo dispuesto en la Ley 27/2006.

82 En este sentido, el apartado A). $1^{\circ}$ del anexo de la Orden AAA/1601/2012. Se consideran abusivas las peticiones de datos de carácter futuro o periódico, cuyo cauce es la difusión (STS de 4 de abril de 2006, recurso de casación núm. 311/2003; y STSJ Comunidad de Madrid núm. 1559/2006, de 26 de septiembre, recurso contencioso-administrativo núm. 1744/2002).

${ }^{83}$ Apartado A). $3^{\circ}$ del anexo de la Orden AAA/1601/2012.

${ }^{84}$ No son documentos inconclusos las actas de inspección del Consejo de Seguridad Nuclear (STS de 17 de febrero de 2004, recurso de casación núm. 3457/2000), ni la información sobre un PORN en tramitación (STS de 28 de octubre de 2003, recurso de casación núm. 3928/1999) ni la documentación correspondiente a los planes de regulación de vertidos relativos a actividades desarrolladas en una determinada provincia por la Confederación Hidrográfica (STS de 3 de octubre de 2006, recurso de casación núm. 2424/2003). Como señala la STS de 29 de noviembre de 2011 (recurso de casación núm. 2071/2008), no se puede confundir un "informe inconcluso" —es decir, en fase de borrador, pendiente todavía, por ejemplo, de firma por su autor o de su preceptiva conformidad por el jefe de la unidad técnica correspondientecon un "expediente inconcluso" en el que figuran sucesivos informes - todos ellos 
tres cambios a fin de precisar y restringir esta excepción [artículo 13.1.d)]: primero, se refiere a material en curso de elaboración y a documentos o datos, no a los expedientes; segundo, se fija un concepto de documento o dato inconcluso, entendiendo por tales "aquellos sobre los que la autoridad pública esté trabajando activamente"; y, tercero, de utilizarse este límite, se añade la garantía adicional de indicar la autoridad que está preparando el material e informar al solicitante del plazo previsto para terminar su elaboración ${ }^{85}$. Así pues, esta limitación se refiere a documentos sin acabar, por lo que no puede invocarse para procedimientos sin terminar, de suerte que los proyectos, informes y otros documentos que forman parte de un expediente tienen sustantividad propia y constituyen soporte de información ${ }^{86}$.

v) La solicitud referida a comunicaciones internas, teniendo en cuenta el interés atendido por la revelación ${ }^{87}$. Esta última limitación, aunque sigue el listado del Convenio de Aarhus, difiere claramente de las restantes de esta lista y supone un claro riesgo de opacidad ${ }^{88}$, por lo que su aplicación estricta exige dos

"conclusos"- a los que se podrán ir añadiendo nuevos datos o resultados de distinto signo conforme avancen las distintas fases del procedimiento administrativo; en este segundo supuesto de "expediente inconcluso" o inacabado, porque todavía carece de resolución final de archivo, los documentos a él incorporados - como son los informes de auscultación del embalse ya emitidos o el Programa de Puesta en Carga - son documentos evidentemente conclusos, aunque el procedimiento administrativo todavía no haya finalizado y no se excluya la posibilidad de que se emitan luego otros informes conforme a los nuevos datos que, en su caso, vayan apareciendo durante la ejecución del proyecto, por lo que debió facilitarse información de los documentos obrantes en los expedientes que, siendo separables, estuvieran -ellos, los documentos-conclusos.

85 La STSJ Castilla y León (Valladolid) 1580/2014, de 23 de julio (recurso de apelación núm. 589/2013), sobre denegación de entrega de informe sobre dinámicas poblacionales del topillo campesino solicitado por SEO/Birdlife, rechaza la concurrencia de este límite al considerarse que "no puede erigirse en argumento para la denegación el hecho de que la metodología empleada haya podido no ser adecuada, ni tampoco que se trate de un inventario que es objeto de sucesivas actualizaciones, ya que ello es distinto del supuesto de los datos inconclusos a que se refiere el artículo 3.3 de la Ley".

${ }^{86}$ De acuerdo con la jurisprudencia que recuerda la SAN 452/2016, de 30 de junio (recurso contencioso-administrativo núm. 3152/2014), no procede esta excepción cuando se trata en suma de documentos que existen "con sustantividad propia, no dependiente de actuación posterior", como puede ser la aprobación o la firma, son "separables" y "los documentos están conclusos". Téngase en cuenta el apartado A). $4^{\circ}$ del anexo de la Orden AAA/1601/2012. En este sentido, la Sugerencia del Defensor del Pueblo de 30 de marzo de 2016 (queja 15016059) considera que un informe geomorfológico de un deslinde no es un documento inconcluso.

87 Según el apartado A). $5^{\circ}$ del anexo de la Orden AAA/1601/2012, en este supuesto, debe entenderse que toda nota, memorándum, correo, etc., que figure en soporte electrónico o papel se considera comunicación interna cuando refleje exclusivamente un intercambio de puntos de vista, opiniones o deliberaciones entre personal al servicio de las Administraciones públicas necesarios para el impulso de la actividad administrativa.

${ }^{88}$ En esa dirección limitativa de la transparencia se sitúa el artículo 70.4 LPACAP, a cuyo tenor no formará parte del expediente administrativo la información que tenga carácter auxiliar o de apoyo que ejemplifica dicho precepto. 
condiciones: que se trate realmente de meras comunicaciones internas y no de otras actuaciones a tomar en consideración en actos externos ${ }^{89}$; y la consideración del interés público atendido por la divulgación de la información, que ha de ponderarse -al igual que en el otro listado- respecto del perjuicio al bien protegido por esta excepción, lo que debe constreñir su alcance.

b) Segunda lista de limitaciones: concurrencia con otros bienes jurídicamente protegidos

La segunda lista de excepciones pretende preservar otros bienes o intereses jurídicamente protegidos que pudieran verse perjudicados por la revelación de la información ambiental solicitada. En vista de la experiencia anterior y siguiendo el Convenio de Aarhus y la Directiva, se ha intentado delimitar mejor su alcance con tres aspectos: se refiere a "extremos", esto es, a cuestiones específicas y concretas, eludiendo la anterior referencia genérica a expedientes; la afectación de la revelación a tales extremos debe ser negativa, pudiendo derivarse un perjuicio para ellos (inciso inicial del artículo 13.2 LIPPJMA) ${ }^{90}$; y se han precisado mejor cada una de las excepciones para favorecer su adecuada y proporcionada aplicación. Estas limitaciones son las siguientes:

i) La confidencialidad de los procedimientos de las autoridades públicas prevista en una norma con rango de ley. Esta formulación sigue la Directiva, pero parece ir más allá del Convenio de Aarhus [art. 4.4.a)], que se refiere al secreto de las deliberaciones de las autoridades públicas ${ }^{91}$. En todo caso, la necesaria cobertura legal —no reglamentaria - contrae este límite a casos restringidos como son las deliberaciones del Consejo de Ministros, que son

\footnotetext{
${ }^{89}$ Así, la Sugerencia del Defensor del Pueblo de 11 de marzo de 2015 (queja 14011733) entiende que los informes técnicos preparatorios de una resolución de fondo sobre un asunto no son meras comunicaciones internas y, por lo tanto, deben ser suministradas al solicitante.

90 Como señala, para el ámbito comunitario, la STG de 13 de enero de 2017 (T-189/14, Deza/ECHA, apartado 52), "ha de demostrarse que el acceso de que se trata puede perjudicar de modo concreto y efectivo al interés protegido por la excepción y que el riesgo de que se perjudique dicho interés es razonablemente previsible y no meramente hipotético".

91 En este sentido, con referencia a la legislación comunitaria, la STJUE de 13 de julio de 2017 (C-60/15 P, Saint-Gobain Glass Deutschland/Comisión, apartados 75 y 76) rechaza la equiparación entre proceso de toma de decisiones y procedimiento administrativo, por entender que el primero no cubre la totalidad de este.
} 
secretas (artículo 5.3 de la Ley 50/1997, de 27 de noviembre, del Gobierno), o las materias "clasificadas" de acuerdo con la Ley de Secretos Oficiales.

ii) Las relaciones internacionales, la defensa nacional o la seguridad pública ${ }^{92}$. Esta amplia formulación debe reconducirse, en razón de la referida exigencia de afectación negativa, a la documentación sensible por tales motivos ${ }^{93}$.

iii) Las causas o asuntos sujetos a procedimiento judicial o en trámite ante los tribunales, al derecho de tutela judicial efectiva o a la capacidad para realizar una investigación penal o disciplinaria, debiendo indicarse en el primer caso el órgano judicial ante el que se $\operatorname{tramitan}^{94}$. Su aplicación, especialmente problemática en los procedimientos administrativos sancionadores, requiere tener en cuenta que la finalidad de este límite estriba en preservar o no perjudicar la buena marcha de la justicia, los derechos de los justiciables y las necesidades de las investigaciones en curso, por lo que no basta la existencia de un procedimiento judicial o sancionador en marcha, sino que es precisa la afectación negativa a este ${ }^{95}$.

\footnotetext{
92 Las excepciones de afectación negativa a determinados intereses, entre los que figura la seguridad pública, no pueden oponerse válidamente a las exigencias de transparencia que se derivan del artículo 25, apartado 4, de la Directiva 2001/18/CE del Parlamento Europeo y del Consejo, de 12 de marzo de 2001, sobre la liberación intencional en el medio ambiente de organismos modificados genéticamente —STJUE de 17 de febrero de 2009 (C-552/07, Azelvandre)-.

${ }^{93}$ En este sentido, véase el apartado B). $2^{\circ}$ del anexo de la Orden AAA/1601/2012.

${ }^{94}$ Aplica esta excepción la STSJ Andalucía (Granada) 2325/2012, de 23 de julio (recurso contencioso-administrativo núm. 681/2007).

${ }^{95}$ En este sentido, el Dictamen 1/2007, de 20 de abril ("Consulta general sobre el acceso a los expedientes sancionadores en materia de medio ambiente"), de la Comisión de Garantía del Derecho de Acceso a la Información Pública de Cataluña, entiende que "el régimen jurídico aplicable a la información relativa a la comisión de infracciones y sanciones administrativas en materia de medio ambiente es exactamente el mismo que establecen los artículos 21.1. b y 23 LTAIPBG para el acceso a la información relativa a cualquier tipo de infracciones y sanciones administrativas, y que se puede resumir en los siguientes términos: no se puede divulgar la identidad de las personas físicas responsables o presuntamente responsables de la comisión de infracciones administrativas (con independencia del estado de tramitación del correspondiente procedimiento) y la Administración puede denegar el acceso a información de los expedientes sancionadores en curso, siempre que lo justifique en el perjuicio que este acceso causaría en la determinación de la responsabilidad infractora o en la efectividad de la sanción"; y que "el hecho de ser abierto o en curso no es motivo suficiente para denegar o limitar el acceso a un expediente determinado, incluso si se trata de expedientes sancionadores. Se podrá denegar el acceso a los expedientes administrativos, incluidos los sancionadores, si causaría un perjuicio para la eficacia de las funciones administrativas de investigación y sanción de las infracciones (riesgo que ciertamente sólo es plausible si el procedimiento implicado está abierto o en curso), no únicamente por el solo hecho de que el expediente esté abierto o en curso". Téngase en cuenta el Informe 145/2008 del Gabinete Jurídico de la Agencia Española de Protección de Datos. Según el apartado B). $3^{\circ}$ del anexo de la Orden AAA/1601/2012, en el caso de los expedientes sancionadores, los documentos que lo integren no serán objeto de publicidad más que a partir del momento en el que el expediente
} 
iv) La confidencialidad de datos de carácter comercial e industrial cuando esté prevista en la ley o en la normativa comunitaria para proteger intereses económicos legítimos, con la finalidad de asegurar las reglas de la libre competencia $^{96}$. Así pues, esta excepción solo opera cuando concurran tres exigencias: cobertura legal o europea97, protección de un legítimo interés económico ${ }^{98}$ y afectación negativa a la confidencialidad de los datos ${ }^{99}$. A tal fin, la Directiva (UE) 2016/943 del Parlamento Europeo y del Consejo, de 8 de junio de 2016, regula la protección de los conocimientos técnicos y la información empresarial no divulgados (secretos comerciales) contra su obtención, utilización y revelación ilícitas, estableciendo una definición amplia de "secreto

finalice. La STSJ País Vasco 605/2011, de 21 de septiembre (recurso contenciosoadministrativo núm. 474/2009), declara, sin referencia en este punto a la Ley 27/2006, el derecho de la asociación ecologista denunciante a que se le comunique la resolución que ponga fin al procedimiento sancionador, pero no el acceso al expediente sancionador.

${ }_{96} \mathrm{El}$ apartado B). $4^{\circ}$ del anexo de la Orden AAA/1601/2012 señala, a título de ejemplo, que, en los casos de proyectos de obras, la divulgación de aquellos elementos de la documentación remitida por el licitador no podrá incluir lo que el propio licitador haya declarado confidencial, con especial consideración a los secretos técnicos, comerciales y demás aspectos confidenciales, conforme a lo previsto en el Real Decreto Legislativo 3/2011, de 14 de noviembre, por el que se aprueba el texto refundido de la Ley de Contratos del Sector Público. En cambio, no afecta a la propiedad intelectual ni industrial el suministro de información relativa a un proyecto técnico que forma parte de un expediente ya divulgado mediante la preceptiva fase de información pública. Véase RAZQUIN LIZARRAGA, M. M., La confidencialidad de los datos empresariales en poder de las administraciones públicas (Unión Europea y España), lustel, Madrid, 2013.

${ }^{97}$ Así, artículo 15 de la Ley 21/2013, de 9 de diciembre, de evaluación ambiental, y artículo 20 de la Ley $9 / 2003$, de 25 de abril, por la que se establece el régimen jurídico de la utilización confinada, liberación voluntaria y comercialización de organismos modificados genéticamente. En este sentido, la STSJ Extremadura 153/2013, de 24 de septiembre (recurso de apelación núm. 126/2013), declara que no es confidencial la información sobre la potabilidad del agua que no está amparada en una norma legal. En cambio, la STSJ Comunidad de Madrid 24/2016, de 14 de enero (recurso contencioso-administrativo núm. 304/2014), confirma la denegación del acceso a la información relativa a la descripción del método a emplear para verificar la potencia de las embarcaciones pesqueras y otros datos, por considerar que, dada la regulación de la materia de control pesquero en un reglamento comunitario, la índole de las medidas que adopta, el ámbito y la extensión de dicho control y la precisa cautela en la utilización y preservación de la información recabada, resulta afectante a la confidencialidad del secreto profesional y comercial del sector pesquero. No obsta a la aplicación de esta excepción (ponderando la oposición del tercero) el hecho de que el interesado no solicitara, durante el procedimiento previsto para la obtención de la autorización, el tratamiento confidencial de la información presentada (STJUE de 23 de noviembre de 2016, C-442/14, Bayer CropScience SA-NV).

98 La STSJ Comunidad Valenciana 201/2015, de 4 de marzo (procedimiento especial de protección jurisdiccional de derechos fundamentales núm. 203/2014), entiende aplicable esta excepción por entender que en la propia acta se señala que las fotos realizadas en el interior de las naves son confidenciales por secreto industrial porque muestran el proceso industrial realizado, así como los datos de temperatura, ciclos, dimensiones de la cámara, número de contenedores y ocupación de la cámara.

${ }_{99}$ Puede considerarse, aunque referida a la normativa comunitaria, la Sentencia del Tribunal General (STG) de 5 de febrero de 2018 (T-235/15, Pari Pharma GmbH contra Agencia Europea de Medicamentos). 


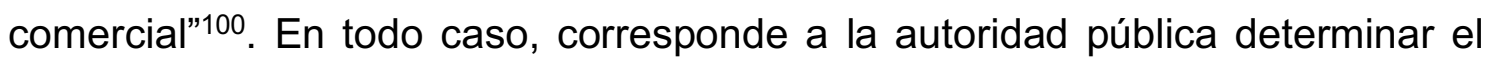
carácter confidencial de la información, sin que haya de estarse necesariamente a la confidencialidad expresada por el interesado ${ }^{101}$.

v) Los derechos de propiedad intelectual o industrial, salvo que el titular haya consentido la divulgación ${ }^{102}$, lo que exige consultar al titular del derecho protegido por esta excepción.

vi) El carácter confidencial de los datos personales, tal y como se regulan en la Ley Orgánica 15/1999, de 13 de diciembre, de Protección de Datos de Carácter Personal, cuando la persona interesada no haya consentido en su tratamiento o revelación ${ }^{103}$. Esta excepción requiere una triple precisión: en primer lugar, a partir del 25 de mayo de 2018 es de aplicación el Reglamento (UE) 2016/679 del Parlamento Europeo y del Consejo, de 27 de abril de 2016, relativo a la protección de las personas físicas en lo que respecta al tratamiento de datos personales y a la libre circulación de estos datos y por el que se deroga la Directiva 95/46/CE (Reglamento general de protección de datos); en segundo lugar, la protección de datos se refiere a las personas físicas (artículo 2.1 Reglamento general de protección de datos), por lo que quedan fuera las personas jurídicas; $y$, finalmente, se exige el consentimiento del interesado sin recogerse una fórmula más completa y equilibrada en adecuada relación entre ambas regulaciones ${ }^{104}$.

\footnotetext{
100 De acuerdo con su artículo 2: "1) 'secreto comercial': la información que reúna todos los requisitos siguientes: a) ser secreta en el sentido de no ser, en su conjunto o en la configuración y reunión precisas de sus componentes, generalmente conocida por las personas pertenecientes a los círculos en que normalmente se utilice el tipo de información en cuestión, ni fácilmente accesible para estas; b) tener un valor comercial por su carácter secreto; c) haber sido objeto de medidas razonables, en las circunstancias del caso, para mantenerla secreta, tomadas por la persona que legítimamente ejerza su control".

101 Aunque referida a la normativa comunitaria, téngase en cuenta la STG de 13 de enero de 2017 (T-189/14, Deza/ECHA).

102 Ténganse en cuenta la Ley de Propiedad Intelectual (texto refundido aprobado por Real Decreto Legislativo 1/1996, de 12 de abril); la Ley 3/2000, de 7 de enero, de régimen jurídico de la protección de las obtenciones vegetales; la Ley 17/2001, de 7 de diciembre, de Marcas; la Ley 20/2003, de 7 de julio, de Protección Jurídica del Diseño Industrial; y la Ley 24/2015, de 24 de julio, de Patentes.

103 Véase el Informe 194/2010 del Gabinete Jurídico de la Agencia Española de Protección de Datos. También LOCATELLI GUTIÉRREZ, M. F., "Derecho de acceso a la información ambiental y protección de datos personales: ponderación de intereses", Revista Aranzadi de Derecho Ambiental, núm. 27, 2014, pp. 251-290.

${ }^{104}$ Según el apartado B). $6^{\circ}$ del anexo de la Orden AAA/1601/2012, lo fundamental en este caso es que se trate de información relativa a personas físicas [la información confidencial de las personas jurídicas está exceptuada en el artículo 13.2.d)], identificadas o identificables, y que pueda afectar a sus derechos fundamentales, como, por ejemplo, a su intimidad, honor y/o
} 
En razón del carácter amplio del concepto de cesión de datos, es una de las excepciones de mayor aplicación ante la tendencia a denegar cualquier información que contenga un nombre como dato personal ${ }^{105}$, por lo que, salvo consentimiento del interesado, solo será posible el suministro parcial de información previa disociación de los datos de carácter personal ${ }^{106}$.

vii) Los intereses o la protección de un tercero que haya facilitado voluntariamente la información sin estar obligado a ello por la legislación vigente, salvo que haya consentido su divulgación ${ }^{107}$. Esta limitación, aunque prevista en el Convenio de Aarhus y la Directiva, resulta extraña a las regulaciones generales de acceso a la información ${ }^{108}$.

viii) La protección del medio ambiente al que se refiere la información solicitada, en particular la relativa a la localización de especies amenazadas o sus lugares de reproducción ${ }^{109}$.

propia imagen. Así, los datos relativos a empresarios individuales, cuando hagan referencia a ellos en su calidad de comerciantes, industriales o navieros, también se entenderán excluidos del régimen de aplicación de la protección de datos de carácter personal. Cuando esta información confidencial pueda separarse del resto de la información ambiental, deberá darse acceso a esta última. En este sentido, la SAN de 23 de diciembre de 2009 (recurso contencioso-administrativo núm. 192/2008) ordena el acceso al listado de embarcaciones de bandera española con licencias especial para cercenar aletas de tiburón por considerar que, aun cuando la información pedida afectase a datos personales, la Administración nada alega respecto a que esa afectación alcance a datos confidenciales y de manera negativa, y siempre sería aplicable la "contraexcepción" prevista en el artículo 2.3 del Reglamento de desarrollo de la LO 15/1999, ya que, de afectar a personas físicas, no lo sería en cuanto tales, sino en su condición empresarial y por razón de su actividad pesquera.

105 Como ha señalado Guichot Reina, un tema capital es que el concepto de dato personal es interpretado hoy de la manera más amplia posible (p. 416); GUICHOT REINA, E., "Acceso a la información en poder de la Administración y protección de datos personales", Revista de Administración Pública, núm. 173, 2007, pp. 407-445. Véase también CASADO CASADO, "EI acceso a la información..." cit., p. 272. Muestra de ello es la STJUE de 29 de junio de 2010 (C28/08P, Bavarian Lager), que aborda esta problemática respecto de la aplicación del Reglamento (CE) núm. 1049/2001, revocando la Sentencia del Tribunal de Primera Instancia de 8 de noviembre de 2007 (T-194/04, Bavarian Lager/Comisión). Véase NIETO GARRIDO, E., "Transparencia y acceso a los documentos versus derecho a la protección de datos de carácter personal en la reciente jurisprudencia del TJUE", Piñar Mañas, J. L., Transparencia, acceso a la información y protección de datos, Ed. Reus, Madrid, 2014, pp. 82-95.

${ }^{106}$ Así, sugerencias del Defensor del Pueblo de 10 de noviembre de 2015 (queja 12247403), sobre expedientes sancionadores, y de 30 de marzo de 2017 (queja 16000143), sobre capturas anuales en cotos de caza.

107 De acuerdo con el apartado B). $7^{\circ}$ del anexo de la Orden AAA/1601/2012, esta excepción no se refiere al objeto, a los datos objetivos de la información, sino a una finalidad: la protección de un tercero.

${ }^{108}$ Así, no está recogida en el artículo 4 del Reglamento (CE) núm. 1049/2001, como indica la STG de 13 de enero de 2017 (T-189/14, Deza/ECHA, apartado 83).

109 De acuerdo con el apartado B). $8^{\circ}$ del anexo de la Orden AAA/1601/2012, mediante esta fórmula se pretende evitar un abuso del derecho para supuestos en los que mediante una solicitud de acceso se pretenda un fin contrario a la preservación del medio ambiente. 
Las excepciones de las letras a), d), f), g) y h) no podrán aplicarse en ningún caso para denegar una solicitud de información relativa a las emisiones al medio ambiente (art. 13.5 LIPPJMA) ${ }^{110}$.

\section{c) Criterios generales de aplicación de las excepciones}

A fin de que las limitaciones se ajusten a su finalidad sin provocar una restricción desproporcionada o injustificada al ejercicio del derecho, se fijan los siguientes criterios generales para su aplicación:

i) El carácter legal y tasado de las excepciones: solo existen y pueden aplicarse los límites expresamente establecidos legalmente, sin que sea posible aplicar otros y en particular los más amplios de la legislación general.

ii) La interpretación restrictiva de las referidas limitaciones, en cuanto excepciones a la regla general de máxima apertura o acceso a la información (art. 13.4 LIPPJMA); por lo que, en caso de duda, la interpretación será favorable a la divulgación de la información ${ }^{111}$.

iii) La aplicación no automática ni general, sino proporcionada y casuística, de estos límites mediante la ponderación circunstanciada de los bienes jurídicos

\footnotetext{
110 Según el apartado sexto de la Orden AAA/1601/2012, deben incluirse en este supuesto las emisiones, vertidos $\mathrm{u}$ otras liberaciones en el medio ambiente que afecten o puedan afectar a los elementos citados en el artículo 2.3.a) (aire, atmósfera, agua, tierra, suelo, paisajes, etc.). La información sobre el tonelaje fabricado o comercializado no es una información relacionada con una emisión al medio ambiente (STG de 23 de septiembre de 2015, T-245/11, ClientEarth y The International Chemical Secretariat, en interpretación del Reglamento núm. 1367/2006). La STJUE de 23 de noviembre de 2016 (C-442/14, Bayer CropScience SA-NV) interpreta el correlativo artículo 4.2, párrafo segundo, de la Directiva 2003/4 en el sentido de que está comprendida en el concepto de emisiones en el medio ambiente la liberación en este de productos o sustancias, como los productos fitosanitarios o biocidas y las sustancias contenidas en ellos, siempre que esta liberación sea efectiva o previsible en condiciones normales o realistas de utilización, así como las indicaciones relativas a la naturaleza, la composición, la cantidad, la fecha y el lugar de las emisiones en el medio ambiente de estos productos o sustancias y los datos relativos a las repercusiones, a más o menos largo plazo, de estas emisiones en el medio ambiente, en particular la información relativa a los residuos presentes en el medio ambiente después de la utilización del producto en cuestión y los estudios sobre la medición de la pérdida de la sustancia durante esta utilización, independientemente de que estos datos provengan de estudios realizados total o parcialmente sobre el terreno, de estudios de laboratorio o de estudios de translocación; en caso de solicitud de acceso a información sobre emisiones en el medio ambiente cuya divulgación afectaría negativamente a uno de los intereses a los que alude el artículo 4.2, párrafo primero, letras a), d) y f) a h), de la Directiva, solo deben divulgarse los datos pertinentes que puedan ser extraídos de la fuente de información que se refieran a las emisiones en el medio ambiente cuando sea posible disociar estos datos del resto de la información contenida en dicha fuente, lo que corresponde comprobar al órgano jurisdiccional remitente.

${ }^{111}$ Así se indica en el apartado sexto de la Orden AAA/1601/2012.
} 
en presencia para determinar el interés prevalente en cada caso ${ }^{112}$. A tal fin, se ponderarán en cada supuesto concreto los intereses en conflicto, el interés atendido por la divulgación y el interés atendido con la denegación (art. 13.4 LIPPJMA) ${ }^{113}$, cuyo riesgo de menoscabo debe ser razonablemente previsible y no hipotético ${ }^{114}$. Además, ha de examinarse si es posible el suministro parcial de la información, separando del texto de la información solicitada la información protegida (art. 14 LIPPJMA).

Ahora bien, no se prevé la tramitación de las solicitudes con la posible intervención de terceros, que bien pueden consentir la revelación en determinados supuestos o bien deben ser oídos cuando sean titulares de bienes o derechos protegidos por alguna de las excepciones, como ocurre en la confidencialidad de los datos de carácter comercial e industrial o los derechos de propiedad intelectual o industrial.

iv) La denegación total o parcial de información debe expresar los motivos de la negativa a facilitarla (art. 13.6 LIPPJMA) ${ }^{115}$. Esta motivación ha de ser específica, sin que sirvan modelos estereotipados, expresar las normas que amparan el bien o interés legítimo protegido y reflejar la ponderación llevada a cabo de los intereses en conflicto. Además, deberán indicarse los recursos pertinentes que puede interponer el solicitante contra la resolución que desestima su solicitud (art. 10, último párrafo, LIPPJMA).

\section{PROTECCIÓN ADMINISTRATIVA Y JUDICIAL DEL ACCESO A LA INFORMACIÓN AMBIENTAL}

\footnotetext{
112 Como señala la STJUE de 16 de diciembre de 2010 (C-266/09, Stichting Natuur en Milieu y otros), la ponderación prescrita del interés público atendido por la divulgación de información medioambiental y del interés específico atendido por la denegación de la divulgación debe efectuarse en cada caso concreto sometido a las autoridades competentes, aun cuando el legislador nacional establezca mediante una disposición de carácter general criterios que permitan facilitar esa apreciación comparada de los intereses en juego.

${ }^{113}$ A esa ponderación se refiere la SAN 452/2016, de 30 de junio (recurso contenciosoadministrativo núm. 3152/2014).

114 STG de 13 de septiembre de 2013 (T-111/11, ClientEarth contra Comisión Europea, ap. 51). 115 Pueden aplicarse acumulativamente varias excepciones (STJUE de 28 de julio de 2011, C71/10, Office of Communications).
} 
Pese a la posibilidad prevista tanto en el Convenio de Aarhus (art. 9.1) como en la Directiva 2003/4/CE (art. 6) ${ }^{116}$ de un procedimiento de recurso ante una entidad independiente e imparcial establecida por la ley, que ha de ser rápido, gratuito o poco costoso y eficaz ${ }^{117}$, la LIPPJMA no fue innovadora en este punto, disponiendo que, contra los actos y las omisiones de las autoridades públicas que contravengan el derecho de acceso a la información, podrán interponerse los recursos administrativos fijados en la Ley 30/1992 -ahora la LPACAP de 2015 - y, en su caso, el recurso contencioso-administrativo previsto en la Ley de la Jurisdicción Contencioso-Administrativa de 1998 [arts. 3,3.a) y 20 LIPPJMA], lo que se complementa mediante un sistema de reclamaciones y ejecución forzosa cuando el incumplimiento proceda de autoridades públicas que no son Administraciones públicas (art. 21 LIPPJMA) $)^{118}$.

Esta tutela administrativa y judicial es uno de los puntos débiles de la regulación especial, ya que remite al sistema general de recursos, tachado de inútil y retardatario, sin establecer un sistema especial, ágil y eficaz que permita la corrección de las infracciones de forma rápida y eficiente, como era posible (art. 107.2 Ley 30/1992) ${ }^{119}$ y se ha previsto después en otros campos ${ }^{120}$, dando continuidad a los principios de agilidad y celeridad del acceso a fin de evitar que la usual demora en el sistema general provoque la pérdida de su finalidad. De ahí que se haya acudido a otros remedios reactivos, como son las quejas ante el Defensor del Pueblo estatal o autonómicos, cuyo papel en este campo

\footnotetext{
116 La STJUE de 6 de octubre de 2015 (C-71/14, East Sussex County Council) es conforme con la Directiva que solo está sujeto a un control administrativo y judicial limitado, como el previsto por el derecho inglés, siempre que dicho control se efectúe sobre la base de elementos objetivos y analice, conforme a los principios de equivalencia y de efectividad, si la autoridad pública que impone una contraprestación económica ha respetado los requisitos previstos en el artículo 5, apartado 2, de la citada Directiva, circunstancia que corresponde comprobar al órgano jurisdiccional remitente.

117 El Informe sobre la aplicación del Convenio de Aarhus en la UE y en España, diciembre 2007 (EEB), recomienda crear mecanismos ágiles, independientes y poco costosos (por ejemplo, comisarios de información o tribunales) para afrontar las solicitudes denegadas.

${ }_{118}$ No recoge, por otro lado, el principio de indemnidad previsto con carácter general en el artículo 5.8 del Convenio de Aarhus.

119 PEÑALVER I CABRÉ, A., "Novedades en el acceso a la justicia y a la tutela administrativa en asuntos medioambientales", Pigrau Solé (dir.), Acceso a la información ... cit., pp. 349-403.

120 Destaca, por su impronta europea, el recurso especial en materia de contratación pública, con la creación de tribunales administrativos de recursos contractuales.
} 
es destacable, si bien en muchos casos infructuoso al no ser sus resoluciones vinculantes ${ }^{121}$.

Finalmente, la protección se ciñe al derecho de acceso, sin contemplarse la posible exigencia del debido cumplimiento de las obligaciones de publicidad activa por las Administraciones públicas, que, dado que de ella deriva un derecho al acceso del público, pudiera articularse también a través del sistema general de recursos ${ }^{122}$.

\section{EL NUEVO PARADIGMA GENERAL DE LA INFORMACIÓN PÚBLICA: LEY DE TRANSPARENCIA Y ACCESO A LA INFORMACIÓN AMBIENTAL}

El nuevo rumbo hacia la transparencia, impulsado desde los principios de libre acceso a la información pública y de gobierno abierto en el panorama comparado e internacional ${ }^{123}$, ha permitido contar recientemente con una ley general del acceso a la información pública. La Ley 19/2013, de 9 de diciembre, de transparencia, acceso a la información pública y buen gobierno (LTAIBG), dictada en desarrollo del artículo 105 CE y vigente desde el 10 de diciembre de 2014 (segundo guión de su disposición final), persigue ampliar y reforzar la transparencia de la actividad pública ${ }^{124}$ y constituye la regulación común del acceso a la información pública ${ }^{125}$, sin perjuicio de la aplicación, en cuanto al

\footnotetext{
121 Es destacable la labor desempeñada en este campo por los defensores del pueblo estatal y autonómicos tanto en la resolución de quejas como mediante otras actuaciones generales para favorecer el cabal ejercicio del derecho de acceso a la información ambiental. Así, la "Recomendación general del Ararteko 6/2010, de 30 de diciembre, Transparencia y derecho de acceso a la documentación pública. En especial, el acceso a la información medioambiental"; y la "Guía del derecho de acceso a la información ambiental" del Defensor del Pueblo Andaluz (2012).

${ }^{122}$ Pese a su dificultad y al margen del acceso por solicitud, pudiera pensarse en un recurso contra la inactividad de la Administración (cfr. art. 25.2 y 29.1 LJCA).

123 Destaca el Convenio del Consejo de Europa sobre el acceso a los documentos públicos, hecho en Tromso el 28 de noviembre de 2008 (todavía no ratificado por España).

${ }^{124}$ El principio de transparencia es un principio general de la actuación de las Administraciones públicas [art. 3.1.c) de la Ley 40/2015, de 1 de octubre, de Régimen Jurídico del Sector Público] y del procedimiento administrativo y de la buena regulación (art. 71.1 y 129 LPACAP).

${ }^{125}$ En su desarrollo, por Real Decreto 919/2014, de 31 de octubre, se aprueba el Estatuto del Consejo de Transparencia y Buen Gobierno. Además de los comentarios a la Ley 19/2013, pueden consultarse, entre otros, RAZQUIN LIZARRAGA, M. M., El derecho de acceso a la información pública: teoría y práctica, en especial, para las entidades locales, IVAP, Oñati, 2016; RAMS RAMOS, L., "El procedimiento de ejercicio del derecho de acceso a la información pública", Revista General de Derecho Administrativo, núm. 41, 2016; y FERNÁNDEZ RAMOS, S. y PÉREZ MONGUIÓ, J. M., El Derecho al Acceso a la Información Pública en España, Aranzadi, Cizur Menor, 2017.
} 
derecho de acceso y en el ámbito de sus competencias, de la correspondiente normativa autonómica (art. 12, párrafo segundo, LTAIBG) ${ }^{126}$.

Esta implantación general del paradigma de la transparencia provoca un cambio de situación o relación con el previo régimen específico de la información ambiental. Ello exige un sucinto contraste entre ambas regulaciones a fin de mostrar sus diferencias en más y en menos y con ello el grado de solapamiento o complementariedad ${ }^{127}$, para luego abordar la relación entre ellas en cuanto al acceso a la información ambiental ${ }^{128}$.

\section{Breve contraste entre régimen general y regulación especial}

La LTAIBG parte también del principio general de acceso a la información pública, con una máxima apertura solo limitada, de forma excepcional, por la preservación de otros bienes jurídicamente protegidos. Asimismo, contempla las dos vertientes del acceso a la información pública, activa y pasiva, aunque con una mayor diversidad entre ambas, tanto en su elemento subjetivo como en el objetivo, pues la definición de información pública no es general, sino que se incardina dentro del derecho al acceso.

En cuanto a los sujetos obligados, se aprecia un amplio solapamiento, pero también claras diferencias, con el ámbito subjetivo fijado por la LTAIBG mediante tres grupos. El primer grupo, comprensivo de las entidades del sector

\footnotetext{
${ }^{126}$ No puede considerarse aquí la legislación autonómica sobre transparencia o buen gobierno con la que cuentan la mayoría de comunidades autónomas.

${ }^{127}$ Como ocurre en la normativa para las instituciones europeas, donde el régimen específico ambiental —Reglamento (CE) núm. 1367/2006 - parte de la anterior regulación general Reglamento (CE) núm. 1049/2001-, fijando especialidades que en parte favorecen y en parte restringen el acceso en el campo ambiental (STJUE de 13 de julio de 2017, C-60/15P, SaintGobain Glass Deutschland GMBH, apartado 65).

${ }^{128}$ CASADO CASADO, L., "Estudio sobre el alcance de la supletoriedad de la Ley 19/2013, de 9 de diciembre, de Transparencia, acceso a la información pública y buen gobierno sobre la Ley 27/2006, de 18 de julio, Reguladora del derecho de acceso a la información ambiental", Revista Vasca de Administración Pública, núm. 99-100, 2014, pp. 819-846; SALAZAR ORTUÑO, E., "Transparencia y acceso a la información ambiental", Valero Torrijos, J. y Fernández Salmerón, M. (coords.), Régimen jurídico de la transparencia del sector público: del Derecho de acceso a la reutilización de la información, Aranzadi, Cizur Menor, 2014, pp. 537558; BLANES CLIMENT, M. Á., "La incidencia de la nueva Ley de Transparencia en Materia Ambiental", Revista Aranzadi de Derecho Ambiental, núm. 28, 2014, pp. 115-150; GUICHOT REINA, E., "El acceso a la información ambiental: relaciones entre normativa general y normativa sectorial. En particular, el sentido del silencio y la garantía de la reclamación ante una autoridad administrativa independiente", Revista Aranzadi de Derecho Ambiental, núm. 33, 2016, pp. 125-162; y CUBERO MARCOS, “EI derecho de acceso..."cit., pp. 131-161.
} 
público (art. 2 LTAIBG), es más amplio que el de las autoridades en sentido estricto para la información ambiental (art. 2.4.1 LIPPJMA); el segundo grupo - limitado a la publicidad activa - no está previsto en la LIPPJMA; y el tercer grupo (art. 4 LTAIBG) parece coincidir con el segundo bloque ambiental (art. 2.4.2 LIPPJMA), si bien aquí se exige la conexión con el medio ambiente.

La publicidad activa se configura también como una obligación de las autoridades públicas y otros sujetos (capítulo II del título I, arts. 5-11), pero se somete a exigencias más concretas como son el control del Consejo de Transparencia y Buen Gobierno (art. 9 LTAIBG), su desarrollo en la AGE del Portal de Transparencia y la sujeción de este a prescripciones técnicas adecuadas a los principios de accesibilidad, interoperabilidad y reutilización (arts. 10-11 LTAIBG).

La faceta pasiva o derecho de acceso a la información pública mediante solicitud (capítulo III del título I, arts. 12-23 LTAIBG) se caracteriza también como un derecho legal (art. 12 LTAIBG), entendiéndose por "información pública los contenidos o documentos, cualquiera que sea su formato o soporte, que obren en poder de alguno de los sujetos incluidos en el ámbito de aplicación de este título y que hayan sido elaborados o adquiridos en el ejercicio de sus funciones" (art. 13 LTAIBG). Esta definición, por su campo objetivo más amplio, se superpone o cubre en buena medida la noción de información ambiental, con la que comparte la amplitud, forma universal y disponibilidad (art. 2.3 LIPPJMA), con la matización de que en aquella, a diferencia de la LIPPJMA, parece deslizarse la regla del autor, ya que la disponibilidad por la autoridad pública no es por sí sola suficiente, sino que se refiere a los contenidos o documentos elaborados o adquiridos por ella.

Las diferencias son relevantes en cuanto a los límites al acceso no solo por el enfoque formalmente dispar de la LTAIBG, que configura la mayoría de las excepciones del primer bloque de la LIPPJMA como supuestos de inadmisión, sino también por la mayor extensión del listado de excepciones referido a la concurrencia con otros bienes o intereses jurídicamente protegidos (art. 14.1 LTAIBG) ${ }^{129}$, que incluye límites —como la política económica y monetaria- no

${ }^{129}$ ARAGUÁS GALCERÁ, I. y otros, Los límites al derecho de acceso a la información pública, INAP, Madrid, 2017. 
previstos en la LIPPJMA (art. 13.2 LIPPJMA), sin perjuicio de solapamientos ${ }^{130}$ y de una regulación más acabada de la protección de los datos de carácter personal (art. 15 LTAIBG). En cambio, se estrechan las diferencias respecto de los criterios de aplicación de las excepciones, que han de aplicarse de forma justificada, proporcionada y ponderando los intereses en conflicto, especialmente la concurrencia de un interés público o privado superior que justifique el acceso (art. 14.2 LTAIBG); asimismo, se prevé el acceso parcial (art. 16 LTAIBG). También aquí las resoluciones denegatorias, de acceso parcial o en forma distinta a la solicitada, así como las que permitan el acceso pese a la oposición de terceros, deben ser motivadas, con indicación del límite o circunstancia que justifica la denegación (art. 20.2 y 3 LTAIBG).

El enfoque formal adoptado por la LTAIBG conlleva una regulación más acabada del procedimiento donde se aprecian claras diferencias en los aspectos que se comentan a continuación. En la tramitación, junto a algunas coincidencias — remisión a la autoridad pública competente en caso de falta de disponibilidad y requerimiento de concreción de la petición con la consecuencia, en otro caso, de entenderse desistida (arts. 19.1 y 2 LTAIBG y 10.2 LIPPJMA)—, se añaden la consulta a terceros cuyos derechos o intereses pudieran resultar afectados por la revelación (art. 19.3 LTAIBG) y la remisión de la solicitud de la información, aun disponible, al sujeto que la haya elaborado o generado en su integridad o parte principal para que decida sobre el acceso (art. 19.4 LTAIBG). Respecto de la resolución, coinciden los plazos máximos, pero su incumplimiento se considera silencio negativo (art. 20.1 y 4 LTAIBG), tipificándose, en caso de ser reiterado, como infracción grave (art. 20.6 LTAIBG). Se contempla expresamente, en razón a la disociación entre resolución y suministro, la formalización del acceso, que se realizará preferentemente por vía electrónica, salvo cuando no sea posible o el solicitante haya señalado expresamente otro medio o esté ya difundida, bien en el mismo momento de la resolución, y, en todo caso, en un plazo no superior a diez días, excepto cuando haya existido oposición de terceros en que el acceso

${ }^{130}$ Así, el Dictamen 1/2007, de 20 de abril ("Consulta general sobre el acceso a los expedientes sancionadores en materia de medio ambiente"), de la Comisión de Garantía del Derecho de Acceso a la Información Pública de Cataluña, respecto de los artículos 13.2.c) LIPPJMA y 14.1.e) LTAIBG. 
solo tendrá lugar cuando haya transcurrido el plazo para interponer recurso contencioso-administrativo sin que se haya formalizado o haya sido resuelto confirmando el derecho a recibir la información (art. 22.1, 2 y 3 LTAIBG). Y se establece la gratuidad del acceso a la información, salvo la expedición de copias o la trasposición de la información a un formato diferente al original (art. 22.4 LTAIBG).

Destaca la diferencia referida a la protección administrativa del derecho de acceso a la información pública. Las resoluciones son susceptibles directamente de recurso contencioso-administrativo (art. 20.5 LTAIBG), si bien se prevé un recurso administrativo especial, de carácter potestativo y sustitutivo de los recursos administrativos ordinarios ${ }^{131}$, consistente en la reclamación ante el Consejo de Transparencia y Buen Gobierno o ante el correlativo órgano autonómico ${ }^{132}$, a interponer en el plazo de un mes y a resolver, previa audiencia en su caso de terceros, en el plazo de tres meses (arts. 23 y 24 LTAIBG $)^{133}$. Las resoluciones de dicho Consejo, que ha de entenderse que son ejecutivas sin perjuicio de su posible impugnación en la vía contenciosoadministrativa, se publicarán previa disociación de los datos de carácter personal que contuvieran y se comunicarán al Defensor del Pueblo (art. 24.5 LTAIBG).

Este rápido contraste apunta tres conclusiones: 1) la regulación específica del acceso a la información ambiental es, en términos generales, más amplia o generosa que la del régimen general o común ${ }^{134}$; 2) en muchos casos, la información ambiental puede ser simultáneamente información pública en razón de los solapamientos entre ambas regulaciones; y 3) en algunos puntos

\footnotetext{
${ }^{131}$ Con la excepción de las resoluciones dictadas por los órganos previstos en el artículo 2.1-f) (art. 23.2 LTAIBG).

${ }^{132}$ La disposición adicional cuarta LTAIBG prevé para las comunidades autónomas y entes locales, así como para las ciudades autónomas, una doble opción en cuanto al conocimiento de las reclamaciones: bien al órgano independiente que determinen las comunidades autónomas o bien al Consejo de Transparencia y Buen Gobierno mediante convenio.

${ }^{133}$ Las resoluciones dictadas por las asambleas legislativas y las instituciones análogas al Consejo de Estado, el Consejo Económico y Social, el Tribunal de Cuentas y el Defensor del Pueblo están excluidas de la reclamación, por lo que solo cabrá la interposición de recurso contencioso-administrativo (disposición adicional cuarta, 1, párrafo segundo, LTAIBG).

${ }^{134}$ CASADO CASADO, "Estudio sobre el alcance..." cit., pp. 826-827; SALAZAR ORTUÑO, "Transparencia y acceso..." cit., p. 558; y FERNÁNDEZ RAMOS y PÉREZ MONGUIÓ, El Derecho al Acceso... cit. pp. 65-66.
} 
—destacadamente el régimen de impugnación-, la diferencia es en menos para la regulación ambiental.

\section{La relación entre la ley general y la ley sectorial en cuanto al acceso a la información ambiental}

En vista del referido contraste, resulta crucial determinar cómo opera la relación entre ambos regímenes, el especial y el general. En cuanto a la publicidad activa, no se suscita problema alguno, ya que la regulación común tiene carácter mínimo, sin perjuicio del régimen más amplio en la legislación específica (art. 5.2 LTAIBG) ${ }^{135}$. En cambio, respecto del derecho de acceso, se fijan dos reglas (DA $1^{\text {a }}$ LTAIBG): las materias que tengan previsto un régimen jurídico específico de acceso a la información se regirán por su normativa específica y por esta ley con carácter supletorio (apartado 2); y esa ley será de aplicación al acceso a la información ambiental en lo no previsto en sus respectivas normas reguladoras (apartado 3$)^{136}$. Así pues, la relación entre ambas regulaciones se ajusta a la regla general siguiente: aplicación preferente de la LIPPJMA y, en lo no previsto en ella, aplicación supletoria de la LTAIBG.

Sin embargo, esa regla general presenta problemas aplicativos por la dificultad de determinar cuándo se está ante una laguna o supuesto no previsto a colmar mediante la aplicación supletoria y sobre todo resulta insuficiente por la acusada peculiaridad de la regulación ambiental dirigida a ampliar o reforzar el acceso a la información como instrumento para asegurar el valor constitucional de la protección del medio ambiente (art. $45 \mathrm{CE}$ ), manifestada en el carácter mínimo de los derechos ambientales, que no excluyen, sino completan o mejoran, los derechos reconocidos en otras normas cuya virtualidad persiste incluso en el campo ambiental (art. 3.4 LIPPJMA) ${ }^{137}$.

\footnotetext{
135 VARGA PASTOR, A. de la, "Estudio de la publicidad activa de la información pública: Especial referencia a la información ambiental y a la aplicación de la Ley 19/2013, de 9 de diciembre, de transparencia, acceso a la información pública y buen gobierno", Revista Catalana de Dret Ambiental, vol. 6, núm. 1, 2015, pp. 1-52.

${ }^{136}$ El Consejo de Trasparencia y Buen Gobierno ha adoptado el Criterio interpretativo, con fecha 12 de noviembre de 2015 (Cl/008/2015), sobre la aplicación de la disposición adicional primera de la Ley 19/2013 sobre regulaciones especiales del acceso a la información pública.

${ }_{137}$ Los artículos 3.5 y 6 del Convenio de Aarhus permiten la continuidad o mejora de las disposiciones que garanticen un acceso más amplio a la información u otros derechos.
} 
La supletoriedad de la LTAIBG respecto del régimen especial de acceso a la información ambiental ha de tener una doble finalidad: en primer lugar, colmar las lagunas existentes en la LIPPJMA, como puede ser la intervención de terceros en los procedimientos; $y$, en segundo lugar, en razón del carácter común o general de la LTAIBG, servir de sustrato básico o general, de carácter mínimo, cuando la información ambiental sea a la vez información pública. No se trata de dos regímenes excluyentes, sino complementarios ${ }^{138}$.

Por lo tanto, son aplicables a la información ambiental las diferencias en más del régimen común, pero no las diferencias en menos ${ }^{139}$. Ello se traduce, negativamente, en la inaplicación de las excepciones y del silencio negativo de la regulación común por el obligado cumplimiento del Convenio de Aarhus y de la Directiva ${ }^{140}, y$, positivamente, en la aplicación del sistema de reclamación o recurso especial ante el Consejo de Transparencia y Buen Gobierno (art. 24 LTAIBG), que se justifica en la coordinación o adaptación de la LIPPJMA al nuevo régimen general e inexcusablemente en los casos mayoritarios en que la información ambiental sea al mismo tiempo información pública, pues el solicitante puede ampararse simultáneamente en ambas regulaciones, so pena de ver mermados los derechos que le reconocen tanto la LIPPJMA (art. 3.4) como la propia LTAIBG $^{141}$.

\footnotetext{
138 Así, Cubero Marcos ("El derecho de acceso..." cit., p. 133) señala que es precisa una interpretación integradora. Véase también CARMONA GARIAS, S., "L'accés a la informació, la participació ciutadana i l'accés a la justícia en matèria de medi ambient a l'àmbit local", Casado Casado, L. y Fuentes i Gasó, J. R. (dirs.), Dret Ambiental Local de Catalunya, Tirant lo Blanch, Valencia, 2017, pp. 120-123.

139 En este sentido, el Dictamen 1/2017, de 20 de abril ("Consulta general sobre el acceso a los expedientes sancionadores en materia de medio ambiente"), de la Comisión de Garantía del Derecho de Acceso a la Información Pública de Cataluña, señala que "las eventuales dudas sobre el alcance de la aplicación supletoria de la legislación de transparencia en el ejercicio del derecho de acceso a la información ambiental deben resolverse en beneficio de la interpretación que sea más favorable al acceso, salvo que no sea en perjuicio de la protección del medio ambiente, supuesto en el que debe prevalecer esta protección".

${ }^{140}$ En igual sentido, FERNÁNDEZ RAMOS, S. y PÉREZ MONGUIÓ, J. M., Transparencia, Acceso a la Información y Buen Gobierno. Ley 19/2013, de 9 de diciembre, Ed. Aranzadi, Cizur Menor, 2014, p. 56; CASADO CASADO, "Estudio sobre el alcance..." cit., pp. 836-838; y FERNÁNDEZ RAMOS y PÉREZ MONGUIÓ, El Derecho al Acceso... cit. p. 67. En contra, GUICHOT REINA, "El acceso a la información ambiental..." cit., pp. 147-149; y BLANES CLIMENT, "La incidencia de..." cit., pp. 133-136 y 147.

${ }^{141}$ Así lo entiende mayoritariamente la doctrina. FERNÁNDEZ RAMOS y PÉREZ MONGUIÓ, Transparencia... cit. p. 56; CASADO CASADO, L., "La reclamación ante el Consejo de Transparencia y Buen Gobierno: ¿Una vía de impugnación aplicable al acceso a la información ambiental?", Revista Catalana de Dret Públic, núm. 52, 2016, pp. 22-42; GUICHOT REINA, "EI acceso a la información ambiental..." cit., p. 156; MARTín DELGADO, I., "La reclamación ante el Consejo de Transparencia y Buen Gobierno: un instrumento necesario, útil y ¿eficaz?",
} 
Sin embargo, no lo ha entendido así el Consejo de Transparencia y Buen Gobierno, que viene inadmitiendo las reclamaciones referidas al acceso a la información ambiental por considerar que, de acuerdo con la disposición adicional primera de la LTAIBG, deben resolverse por la normativa específica (LIPPJMA) ${ }^{142}$, criterio que no es uniforme en los órganos autonómicos ${ }^{143} \mathrm{y}$ del que discrepa el Defensor del Pueblo por considerar que la LIPPJMA no dispone de un dispositivo "específico" de recurso en materia ambiental, sino que recoge los previstos en la legislación general ${ }^{144}$.

\section{RETOS DE FUTURO}

El Convenio de Aarhus ha dado en sus veinte años frutos importantes en el desarrollo y avance del acceso a la información ambiental, cuya implantación presenta un balance general positivo. La LIPPJMA constituye una regulación avanzada del primer pilar y su aplicación ha propiciado, con el auxilio de la jurisprudencia, la expansión y efectividad del acceso a la información ambiental tanto en la dimensión activa (amplia difusión de publicidad activa a través de medios telemáticos) como en la pasiva (elevado número de solicitudes de información presentadas y resueltas $)^{145}$.

López Ramón, F. (coord.), Las vías administrativas de recurso a debate: Actas del XI Congreso de la Asociación Española de Profesores de Derecho Administrativo, Zaragoza, 5 y 6 de febrero de 2016, INAP, Madrid, 2016, pp. 422-423; y FERNÁNDEZ RAMOS y PÉREZ MONGUIÓ, El Derecho al Acceso... cit. pp. 67-68. En contra, BLANES CLIMENT, "La incidencia de..." cit., pp. 147-148.

142 Resoluciones de 18 de agosto de 2017 (R/0230/2017), de 24 de octubre de 2017 (R/0369/2017) y de 4 de diciembre de 2017 (R/0503/2017). No obstante, otras resoluciones, pese a tratarse de información ambiental, conocen del asunto y aplican la legislación general, si bien con resultado desestimatorio (resoluciones de 1 de diciembre de 2017, R/0416/2017, y de 4 de diciembre de 2017, R/0417/2017).

${ }^{143}$ Así, la Comisión de Transparencia y Protección de Datos de Andalucía sigue el criterio del Consejo estatal al inadmitir las reclamaciones referidas a información ambiental (Resolución 53/2018, de 16 de febrero); en cambio, la Comisión de Garantía del Derecho de Acceso a la Información Pública de Cataluña se ha declarado competente para conocer también de tales reclamaciones (resoluciones 211/2017, de 27 de junio, y 325/2017, de 22 de septiembre).

${ }^{144}$ Recomendación de 2 de enero de 2018 (queja 16015570).

${ }^{145}$ Pueden consultarse, en sus respectivas páginas web referidas a la información ambiental, las estadísticas sobre solicitudes de información ambiental que, en cumplimiento de la DA $8 .^{a}$ LIPPJMA, publican las Administraciones públicas. Según el Informe estadístico 2016 sobre acceso a la información ambiental, pp. 31-94, del Ministerio de Agricultura y Pesca, Alimentación y Medio Ambiente (www.mapama.gob.es/es/.../informacion/informacionambiental/informes-estadisticos/ [Última consulta, 23 de abril de 2018]), p. 103, en el año 2016 se presentaron 32.439 solicitudes en el MAPAMA, 89.997 en ministerios y 97.207 en ocho comunidades autónomas. 
Ahora bien, como se ha reflejado y muestra la experiencia (informes, quejas, recursos) ${ }^{146}$, todavía persisten dificultades y disfunciones para una cabal y efectiva aplicación del primer pilar ${ }^{147}$, como son la falta de resolución o silencio, el incumplimiento de los plazos, la denegación fundada en la incorrecta interpretación de algunas excepciones o los problemas en los entes locales. Los claros avances no pueden ocultar la pervivencia de vestigios del obsoleto criterio de opacidad que todavía arrojan sombras o barreras para la plena normalización del principio general de transparencia y acceso a la información ambiental.

La posterior aprobación de la regulación común del derecho de acceso a la información pública en la LTAIBG impone una profundización o renovada configuración más avanzada del primer pilar de información ambiental a partir del nuevo paradigma general —que es suelo, y no techo-, proyectando la especial sensibilidad y la dimensión colectiva y fiduciaria del medio ambiente. Sin perjuicio de una modificación legal, la relación entre regulación específica y general no debe ser de exclusión, sino de complementariedad, de suerte que la cobertura del derecho de acceso a la información ambiental sea el resultado de la suma de ambos regímenes.

Así pues, pese a los importantes progresos, existe un margen de mejora de la regulación y efectividad del acceso a la información ambiental ${ }^{148}$, pudiendo formularse algunas propuestas de avance o retos futuros, como serían las siguientes:

a) Configuración del acceso a la información ambiental como un derecho fundamental. Como se ha indicado, los derechos de acceso a la información ambiental (art. 3 LIPPJMA) y a la información pública (art. 12 LTAIBG) están configurados como derechos legales y no fundamentales.

\footnotetext{
${ }^{146}$ Así, el Defensor del Pueblo, Informe anual 2017, p. 831, recoge el resultado de la encuesta sobre transparencia (que incluye el medio ambiente), señalando la información insuficiente, el retraso en la respuesta y la dificultad de entender el lenguaje de la Administración.

147 Informe de cumplimiento presentado por España a la Reunión de las Partes del Convenio de Aarhus, de fecha 28 de noviembre de 2016. Véanse los informes anuales del Defensor del Pueblo, en concreto, Informe anual 2017, p. 831.

148 Téngase en cuenta la "Decisión VI/1 Promoting effective access to information", adoptada en la sexta sesión de la Reunión de las Partes del Convenio de Aarhus, celebrada en Budva, Montenegro, 11-14 de septiembre de 2017 (ECE/MP.PP/2017/2/Add.1).
} 
Ahora bien, existen elementos que permiten avanzar en la consideración del acceso a la información ambiental como un derecho humano o fundamental. Desde una perspectiva sectorial, la jurisprudencia del TEDH, aunque no ha reconocido un derecho autónomo al medio ambiente ${ }^{149}$, protege una dimensión ambiental o un ambiente saludable en casos de degradación ambiental grave o severa con base en el artículo $8 \mathrm{CEDH}$ (a partir de la STEDH de 9 de diciembre de 1994, asunto López Ostra contra España), que cubre el derecho del público a recibir informaciones que permitan evaluar el peligro al que se expone (STEDH de 19 de febrero de 1998, caso Guerra contra Italia) ${ }^{150} \mathrm{y}$, en su faceta también procedimental, el acceso público a las conclusiones de los estudios ambientales (STEDH, Sección 3. a , de 10 de noviembre de 2004, caso Taskin contra Turquía, parágrafo 115$)^{151}$, así como ha señalado el destacado papel del derecho a la libertad de expresión y de comunicación (art. $10 \mathrm{CEDH}$ ) en materia de medio ambiente, que protege la libre comunicación de información por las asociaciones ambientales ${ }^{152}$. Además, la protección del medio ambiente aparece entre los derechos recogidos en la Carta de Derechos Fundamentales de la Unión Europea (artículo 37); y en el ámbito interno, algunas reformas estatutarias han incluido en el catálogo de derechos, con distintas fórmulas, el derecho a un medio ambiente equilibrado, sostenible y saludable, así como el derecho al acceso a la información medioambiental, por lo que ambos se configuran como "derechos estatutarios"153. Asimismo, en el plano internacional

\footnotetext{
149 STEDH de 22 de mayo de 2003 (caso Kyrtatos contra Grecia).

150 En cambio, esta STEDH rechaza que la libertad de recibir informaciones (art. 10.2 CEDH) pueda entenderse en el sentido de imponer a los Estados, en circunstancias tales como las del presente caso, obligaciones positivas de recogida y difusión, motu propio, de informaciones.

151 Entre otros, SAN MARTíN SEGURA, D., "La «ecologización» de los derechos fundamentales en el marco del Convenio Europeo de los Derechos Humanos", Revista de Derecho de la Universidad de La Rioja, núm. 3, 2005, pp. 221-261; SALLES CAVEDÓN, F. de, "La construcción de una dimensión ambiental de los derechos humanos por la jurisprudencia de la Corte Europea de Derechos Humanos: el derecho de acceso a la información y a la libertad de expresión en materia ambiental", Revista Aranzadi de Derecho Ambiental, núm. 14, 2008, pp. 137-155; y SIMÓN YARZA, F., "La construcción de la tutela ambiental en la jurisprudencia de Estrasburgo", Persona y Derecho, núm. 63, 2010, pp. 87-110.

152 Entre otras, STEDH de 27 de mayo de 2004 (asunto Vides Aizsardzības Klubs contra Letonia).

${ }^{153}$ Así, el artículo 27 del Estatuto de Autonomía de Cataluña de 2006 reconoce expresamente el derecho de todas las personas a acceder a la información medioambiental de que disponen los poderes públicos, que solo puede ser limitado por motivos de orden público justificados, en los términos que establecen las leyes (artículo 27.3), lo que le confiere la especial protección del Consejo de Garantías Estatutarias (arts. 37 y 38), así como la del Síndic de Greuges (art. 78). En cambio, la difusión de la información se incluye entre los principios rectores (art. 46.5). Véase, entre otros, PEÑALVER I CABRÉ, A., "El derecho humano al medio ambiente y su
} 
se destaca la interdependencia entre derechos humanos y protección ambiental, y el acceso a la información ambiental se incluye dentro del derecho humano de toda persona a la información ${ }^{154}$.

Y, desde una óptica general, esa caracterización vendría cubierta por la consideración del derecho de acceso a la información pública como derecho fundamental, con base en la doctrina del TEDH ${ }^{155}$ y en la inclusión del derecho de acceso a los documentos en la Carta de Derechos Fundamentales de la Unión Europea (art. 42) ${ }^{156}$.

De configurarse como derecho fundamental, el derecho de acceso a la información ambiental gozaría de una posición preferente respecto de otros derechos no fundamentales y se beneficiaría de una especial y reforzada protección constitucional y judicial.

protección efectiva", Revista Vasca de Administración Pública, núm. especial 99-100, 2014, pp. 2333-2357.

${ }^{154}$ El Informe del Relator Especial sobre la cuestión de las obligaciones de derechos humanos relacionadas con el disfrute de un medio ambiente sin riesgos, limpio, saludable y sostenible (24 de enero de 2018), de Naciones Unidas, recoge, en su anexo "Principios marco sobre los derechos humanos y el medio ambiente", el "Principio marco 7: Los Estados deben proporcionar acceso público a la información ambiental mediante la reunión y difusión de datos y proporcionar un acceso asequible, efectivo y oportuno a la información a cualquier persona que lo solicite", considerando que el derecho humano de todas las personas a buscar, recibir e impartir información incluye la información sobre cuestiones ambientales (UN Doc. A/HRC/37/59). Asimismo, PRIEUR, M., "El proyecto de Pacto internacional sobre el derecho de los seres humanos al medio ambiente", Revista Aranzadi de Derecho Ambiental, núm. 38, 2017, pp. 93-119. Dicho Pacto ha sido elaborado por el Centro Internacional de Derecho Comparado del Medio Ambiente (CIDCE), cuyo artículo 9 recoge el derecho a la información.

155 SSTEDH de 25 de junio de 2013 (caso Youth Initiative for Human Rights contra Serbia), que declara (apartado 20): "La noción de 'libertad de recibir información' incluye el derecho de acceso a la información, que ha de reconocerse no solo a los medios de comunicación"; de 28 de noviembre de 2013 (Caso Österreichische Vereinigung Zur Erhaltung, Stärkung Und Schaffung Eines Wirtschaftlich Gesunden Land-Und Forst-Wirtschaftlichen Grundbesitzes contra Austria); y de 8 de noviembre de 2016 (caso Magyar Helsinki Bizottság contra Hungría). Véase RAZQUIN LIZARRAGA, J. A., "Acerca de la naturaleza del derecho de acceso a la información pública (A propósito de la STEDH de 28 de noviembre de 2013)", Revista Aranzadi Doctrinal, núm. 11/2014.

${ }^{156}$ Así, RAMS RAMOS, L., "La transformación del derecho de acceso en España: de derecho de configuración legal a derecho fundamental", Revista Española de Derecho Administrativo, núm. 160, 2013, pp. 155-188; COTINO HUESO, L., "El derecho fundamental de acceso a la información, la transparencia de los poderes públicos y el gobierno abierto. Restos y oportunidades", Valero Torrijos, J. y Fernández Salmerón, M. (coords.), Régimen Jurídico de la transparencia del sector público. Del derecho de acceso a la reutilización de la información, Aranzadi, Cizur Menor, 2014, pp. 49-52; y PIÑAR MAÑAS, J. L., "Transparencia y derecho de acceso a la información pública. Algunas reflexiones en torno al derecho de acceso en la Ley 19/2013, de Transparencia, Acceso a la Información y Buen Gobierno", Revista Catalana de Dret Públic, núm. 49, 2014, pp. 1-19, quien sostiene que la LAITBG debería haber configurado el derecho de acceso a la información pública como un verdadero derecho fundamental y no solo como una manifestación de la transparencia en cuanto principio de actuación de las Administraciones públicas. 
b) Organización del acceso a la información ambiental. La amplitud de la información ambiental exige una adecuada organización que permita la sencilla y ágil accesibilidad a ella por el público, pudiendo avanzarse mediante el establecimiento de un servicio integral de información ambiental ${ }^{157}$ que abarque las dos facetas -activa y pasiva - y esté dotado de los recursos materiales y humanos necesarios. Una red específica de soporte y apoyo para el cumplimiento de todas las obligaciones de divulgación y acceso a la información ambiental ${ }^{158}$.

c) Accesibilidad, interoperabilidad, calidad y amplitud de la difusión de la información por las autoridades públicas. Los tres elementos de la faceta activa —recogida, actualización y difusión - conllevan la publicidad de una información completa, precisa, actual, sistematizada y comparable. Para ello, debe avanzarse en varias direcciones: 1) facilitar un contenido informativo amplio sobre todas las actividades o productos con relevancia ambiental159, prestando especial atención a la recogida y actualización de la información en cuanto instrumento de verificación de la actuación pública y en particular del adecuado desarrollo de las funciones de supervisión e inspección, con especial consideración de la liberalización de actividades mediante las técnicas de la comunicación y de la declaración responsable que dificultan la transparencia ${ }^{160}$; 2) crear un portal general de información ambiental que incluya el contenido

\footnotetext{
${ }^{157}$ El Ararteko en su Informe al Parlamento Vasco de 2006 ya propuso la implantación de un servicio de información integral.

${ }^{158}$ En este sentido, la Red de Información Ambiental de Andalucía (REDIAM), que tiene como objeto la integración, normalización y difusión de toda la información sobre el medio ambiente andaluz generada por todo tipo de centros productores de información ambiental en la Comunidad Autónoma (Ley 7/2007, de 9 de julio, de Gestión Integrada de la Calidad Ambiental, y Decreto 347/2011, de 22 de noviembre); y el Centro de Información y Documentación Ambiental (CIDAM), que unifica la gestión del acceso (tramitación y propuesta) para todos los entes del sector público de la Generalitat Valenciana (Decreto 97/2010, de 11 de junio, modificado por Decreto 49/2017). En el ámbito comparado, puede mencionarse la Red SINAnet en Italia, a la que se refiere TRIAS PRATS, B., "Veinticinco años de acceso a la información en Italia: de la Ley 349/1986 a la Directiva Inspire", Revista de Administración Pública, núm. 1888, 2012, pp. 393-420.

159 El Real Decreto 110/2015, de 20 de febrero, sobre residuos de aparatos eléctricos y electrónicos, recoge obligaciones de información de las Administraciones públicas (arts. 51 y 52) y la puesta en marcha de una plataforma electrónica de gestión de RAEE donde se recopilará la información sobre la recogida y gestión de RAEE procedente de todos los canales y agentes previstos en este real decreto, en cada comunidad autónoma y en el ámbito estatal (art. 55 y disposición transitoria octava).

160 CASADO CASADO, L., "Inspección ambiental y liberalización de servicios y actividades económicas", Sanz Larruga, J. (dir.) y otros, Libre mercado y protección ambiental: intervención y orientación ambiental de las actividades económicas, INAP, Madrid, 2013, p. 184.
} 
informativo específico exigido por la LIPPJMA y también integre, al nivel correspondiente, toda la información, bien de forma directa o mediante enlaces a las bases de datos correspondientes; 3) garantizar la interoperabilidad de los distintos medios o puntos de divulgación, así como una adecuada agregación de datos; 4) extender el contenido de la información a los datos con relevancia ambiental, como puede ser la información sobre las sustancias peligrosas para la salud o el medio ambiente en los productos comercializados; y 5) establecer la comunicación y accesibilidad plena y normalizada por medios electrónicos, pasando de los propósitos de la LIPPJMA a la materialización de las exigencias de implantación de la Administración electrónica de la legislación actual ${ }^{161}$, e incorporando también el acceso desde dispositivos móviles en transposición de la normativa comunitaria ${ }^{162}$. En suma, debe avanzarse hacia el uso de los datos abiertos (open data) en aras de la protección del medio ambiente ${ }^{163}$, dando el salto desde la publicidad pasiva a la activa ${ }^{164}$.

d) Mejora de la regulación del derecho de acceso a la información ambiental mediante solicitud: la faceta pasiva debe revisarse, de forma directa (modificación legal) o indirecta (interpretación), en línea con los avances presentes en la regulación general del acceso a la información pública (LTAIBG). A tal fin, ha de ampliarse el primer bloque de autoridades ambientales (art. 2.4.1 LIPPJMA) hasta coincidir con el ámbito subjetivo -más amplio— del derecho de acceso a la información pública (art. 2.1 LTAIBG); la presentación y el suministro han de ser —al margen de consulta telefónica o in situ- por medios telemáticos; ha de completarse la tramitación de las solicitudes de información ambiental contemplando la intervención de terceros afectados por las excepciones; y debe establecerse la regla general de gratuidad del suministro en correspondencia con su entrega en formato

${ }^{161}$ CERILLO I MARTÍNEZ, A., "El uso de medios electrónicos en la difusión de la información pública", Régimen jurídico de la transparencia... cit., pp. 323-366.

162 Directiva (UE) 2016/2102 del Parlamento Europeo y del Consejo, de 26 de octubre de 2016, sobre la accesibilidad de los sitios web y aplicaciones para dispositivos móviles de los organismos del sector público.

163 SANZ LARRUGA, J., "La administración electrónica como instrumento de protección ambiental. En particular, los servicios electrónicos de información ambiental (2003-2013)", Balcells Padullés, J. y otros (coords.), Internet, derecho y política una década de transformaciones: Actas del $X$ Congreso Internacional Internet, Derecho y Política, Universitat Oberta de Catalunya, Barcelona, 2014, pp. 563-564.

164 Como propuso GUICHOT, E., Transparencia y acceso a la información pública en España: análisis y propuestas legislativas, Documento de trabajo 170/2011, p. 57. 
electrónico —corriendo a cargo de la autoridad pública la digitalización-, salvo que el solicitante pida copias de documentos. Desde la perspectiva de la efectividad, debe facilitarse el acceso mediante un buzón o instancia electrónica y resolverse en plazo todas las solicitudes, con el inmediato suministro de la información solicitada, salvo denegación excepcional y justificada. La regla general debe ser la informalidad en la obtención de información ambiental (petición e inmediato suministro), salvo los casos de obligada intervención de terceros o de denegación total o parcial.

e) Revisión legal y aplicativa de las excepciones: pese a la mejor formulación legal e interpretativa ${ }^{165}$, continúan las disfunciones y los conflictos en su aplicación, que se centran principalmente en cinco limitaciones. La falta de disponibilidad de la información no puede encubrir el incumplimiento de las funciones de seguimiento, supervisión o inspección que corresponden a las Administraciones públicas, por lo que están obligadas, en ejercicio de esas competencias, a recoger y disponer de las informaciones correspondientes para facilitar el posterior acceso del público a ellas. Es preciso adecuar la aplicación práctica de la limitación referida a los documentos en curso de elaboración a sus justos términos legales, de suerte que sea excepcional por referencia a documentos sin acabar, que deberán ser suministrados de forma inmediata a su terminación. Asimismo, la excepción sobre las comunicaciones internas debe reorientarse a fin de impedir que entrañe opacidad de la información, por lo que, por regla general especialmente para las autoridades en sentido estricto, tendrá primacía el interés protegido por la divulgación, pues no puede servir de pretexto para la ocultación de información. La protección de la confidencialidad de los secretos empresariales, pese a su importancia, debe ser ponderada de forma estricta y proporcionada teniendo en cuenta las tres exigencias legales y el interés protegido por la revelación, por lo que debe ceñirse a los datos imprescindibles y exigir la adecuada justificación a quien se oponga a la revelación. Y, finalmente, ha de atemperarse la interpretación expansiva de la protección de los datos de carácter personal, que frecuentemente veda el acceso o permite solo el suministro parcial —salvo en caso de consentimiento del interesado-, teniendo en cuenta que la exclusión

${ }^{165}$ Como se ha visto, recogidas en el anexo de la Orden AAA/1601/2012. 
generalizada de la identificación de personas físicas no parece siempre justificada, bien por no afectar a datos especialmente protegidos $^{166}$, bien porque en muchos casos actúan realmente como empresarios (actividades sujetas a licencia) o bien porque la propia legislación ambiental pondera exigencias personales de cualificación y prevé responsabilidades específicas de tales personas ${ }^{167}$. El necesario equilibrio entre el acceso a la información ambiental y la protección de datos de carácter personal ${ }^{168}$ exige una reformulación de esta excepción en el campo ambiental en línea con la fórmula más depurada del artículo 15 LTAIBG, así como una aplicación muy ponderada que tenga en cuenta la especial sensibilidad del medio ambiente.

Es necesaria una aplicación restrictiva de las excepciones en la práctica a fin de impedir el menoscabo del derecho de acceso a la información ambiental, teniendo en cuenta, cuando sean las solicitantes, el especial papel conferido a las organizaciones ambientales o asociaciones ecologistas [arts. 2.2.b), 22 y 24 LIPPJMA], así como previendo —al igual que en el régimen general— la publicidad de las resoluciones denegatorias.

f) Protección eficaz del acceso a la información ambiental mediante un recurso especial: para reparar el punto más débil de la regulación específica del acceso a la información ambiental, es necesario extender a este campo - mediante una reforma legal, en su caso- el sistema de reclamaciones o recurso

\footnotetext{
166 Como señala el Defensor del Pueblo en su Informe anual 2017, p. 705, en relación con la queja planteada por una sociedad local de cazadores que pidió a la Administración el acceso al expediente tramitado para la modificación de un coto de caza, titularidad de dicha sociedad, para la constitución de uno nuevo, con terrenos segregados del primero, a favor de un tercero que lo solicitó.

${ }_{167}$ Así, el artículo 16 de la Ley 21/2013, de 9 de diciembre, de evaluación ambiental, sobre capacidad técnica y responsabilidad del autor de los estudios y documentos ambientales.

${ }^{168}$ El artículo 86 del Reglamento (UE) 2016/679 se refiere a la conciliación del acceso del público a documentos oficiales con el derecho a la protección de los datos personales. En este sentido, GUICHOT REINA, E., "Derecho a la privacidad, transparencia y eficacia administrativa: un difícil y necesario equilibrio", Revista Catalana de Dret Públic, núm. 35, 2007, pp. 43-74; PIÑAR MAÑAS, J. L., "Transparencia y protección de datos: las claves de un equilibrio necesario", Ruiz Ojeda, A. (coord.), El gobierno local. Estudios en homenaje al Profesor Luis Morell Ocaña, lustel, Madrid, 2010, pp. 1023-1044; MARTÍNEZ MARTíNEZ, R., "De la opacidad a la casa de cristal. El conflicto entre privacidad y transparencia", Régimen jurídico de la transparencia... cit., pp. 241-280; PIÑAR MAÑAS, J. L., "Transparencia y protección de datos. Una referencia a la Ley 19/2013, de 9 de diciembre, de transparencia, acceso a la información y buen gobierno", Piñar Mañas, J. L., Transparencia, acceso a la información y protección de datos, Ed. Reus, Madrid, 2014, pp. 45-62; y RODRÍGUEZ ÁLVAREZ, J. L., "Transparencia y protección de datos personales: criterios legales de conciliación", Canals i Ametller, D. (ed.), Datos. Protección, transparencia y buena regulación, Documenta Universitaria, Girona, 2016, pp. 53-85.
} 
especial en materia de acceso a la información pública (art. 24 LTAIBG), que, por otro lado, puede mejorarse configurándolo como un procedimiento telemático y reduciendo el plazo de resolución a dos meses en consonancia con el principio de agilidad en el acceso.

En suma, si la información es poder y el poder procede del pueblo, que ostenta el derecho-deber a un medio ambiente adecuado, es necesario empoderar a todas las personas con el más amplio acceso a la información ambiental. Debe proseguir el avance hacia la plena y renovada implantación efectiva del primer pilar del Convenio de Aarhus para favorecer una democracia informada, participativa y responsable que garantice la protección del medio ambiente y contribuya al desarrollo sostenible.

\section{BIBLIOGRAFÍA}

ARAGUÁS GALCERÁ, Irene y otros, Los límites al derecho de acceso a la información pública, INAP, Madrid, 2017.

BERTAZO, Silvia, "El acceso a la información ambiental en la Unión Europea. La normativa general y los aspectos relevantes para el derecho al agua", Revista General de Derecho Administrativo, núm. 46, 2107.

BLANES CLIMENT, Miguel Ángel, "La incidencia de la nueva Ley de Transparencia en Materia Ambiental", Revista Aranzadi de Derecho Ambiental, núm. 28, 2014.

CARMONA GARIAS, Silvia, "L'accés a la informació, la participació ciutadana i l'accés a la justícia en matèria de medi ambient a l'àmbit local", Casado Casado, Lucía y Fuentes i Gasó, Josep Ramon (dirs.), Dret Ambiental Local de Catalunya, Tirant lo Blanch, Valencia, 2017, pp. 89-149.

CASADO CASADO, Lucía, "El derecho de acceso a la información ambiental previa solicitud", en Pigrau Solé, Antoni (dir.), Acceso a la información, participación pública y acceso a la justicia en materia de medio ambiente: diez años del Convenio de Aarhus, Atelier, Barcelona, 2008, pp. 225-298.

- "El derecho de acceso a la información ambiental a través de la jurisprudencia”, Revista de Administración Pública, núm. 178, 2009. 
- "El acceso a la información ambiental en España: luces y sombras", Derecho PUCP: Revista de la Facultad de Derecho, núm. 70, 2013.

- "Inspección ambiental y liberalización de servicios y actividades económicas", Sanz Larruga, Javier (dir.) y otros, Libre mercado y protección ambiental: intervención y orientación ambiental de las actividades económicas, INAP, Madrid, 2013, pp. 143-191.

- "Estudio sobre el alcance de la supletoriedad de la Ley 19/2013, de 9 de diciembre, de Transparencia, acceso a la información pública y buen gobierno sobre la Ley 27/2006, de 18 de julio, Reguladora del derecho de acceso a la información ambiental", Revista Vasca de Administración Pública, núm. 99-100, 2014,

- "La reclamación ante el Consejo de Transparencia y Buen Gobierno: ¿Una vía de impugnación aplicable al acceso a la información ambiental?”, Revista Catalana de Dret Públic, núm. 52, 2016.

CERILLO I MARTÍNEZ, Agustí, "El uso de medios electrónicos en la difusión de la información pública", Valero Torrijos, Julián y Fernández Salmerón, Manuel (coords.), Régimen Jurídico de la transparencia del sector público. Del derecho de acceso a la reutilización de la información, Aranzadi, Cizur Menor, 2014, pp. 323-366.

COTINO HUESO, Lorenzo, "El derecho fundamental de acceso a la información, la transparencia de los poderes públicos y el gobierno abierto. Restos y oportunidades", Valero Torrijos, Julián y Fernández Salmerón, Manuel (coords.), Régimen Jurídico de la transparencia del sector público. Del derecho de acceso a la reutilización de la información, Aranzadi, Cizur Menor, 2014, pp. 49-52.

CUBERO MARCOS, José Ignacio, "El derecho de acceso a la información ambiental y su adaptación a la normativa general sobre transparencia administrativa: algunos casos controvertidos", Revista Aranzadi de Derecho Ambiental, núm. 37, 2017.

FERNÁNDEZ RAMOS, Severiano y PÉREZ MONGUIÓ, José M. ${ }^{a}$, Transparencia, Acceso a la Información y Buen Gobierno. Ley 19/2013, de 9 de diciembre, Ed. Aranzadi, Cizur Menor, 2014. 
- El Derecho al Acceso a la Información Pública en España, Aranzadi, Cizur Menor, 2017.

GARCÍA URETA, Agustín María, "Ejecución de la política ambiental europea, transparencia y acceso a la información sobre aspectos económicos", García Macho, Ricardo Jesús, Ordenación y transparencia económica en el Derecho público y privado, Marcial Pons, Madrid, 2014, pp. 213-242.

GONZÁLEZ BONDIA, Alfonso, "La regulación comunitaria europea del acceso a la información, la participación pública y el acceso a la justicia en materia de medio ambiente en sus estados miembros", en Pigrau Solé, Antoni (dir.), Acceso a la información, participación pública y acceso a la justicia en materia de medio ambiente: diez años del Convenio de Aarhus, Atelier, Barcelona, 2008, pp. 85-118.

GUICHOT REINA, Emilio, "Derecho a la privacidad, transparencia y eficacia administrativa: un difícil y necesario equilibrio", Revista Catalana de Dret Públic, núm. 35, 2007.

- "Acceso a la información en poder de la Administración y protección de datos personales", Revista de Administración Pública, núm. 173, 2007.

- Transparencia y acceso a la información pública en España: análisis y propuestas legislativas, Documento de trabajo 170/2011.

- "El acceso a la información ambiental: relaciones entre normativa general y normativa sectorial. En particular, el sentido del silencio y la garantía de la reclamación ante una autoridad administrativa independiente", Revista Aranzadi de Derecho Ambiental, núm. 33, 2016.

LOCATELLI GUTIÉRREZ, María Florencia, "Derecho de acceso a la información ambiental y protección de datos personales: ponderación de intereses", Revista Aranzadi de Derecho Ambiental, núm. 27, 2014.

MARTÍN DELGADO, Isaac, "La reclamación ante el Consejo de Transparencia y Buen Gobierno: un instrumento necesario, útil y ¿eficaz?", López Ramón, Fernando (coord.), Las vías administrativas de recurso a debate: Actas del XI Congreso de la Asociación Española de Profesores de Derecho Administrativo, Zaragoza, 5 y 6 de febrero de 2016, INAP, Madrid, 2016, pp. 291-328. 
MARTÍNEZ GUTIÉRREZ, Rubén, "El silencio administrativo en el acceso a la información ambiental (Comentario a la STJCE de 21 de abril de 2005, asunto C-.186-04)", Revista Aranzadi de Derecho Ambiental, núm. 9, 2006.

MARTÍNEZ MARTÍNEZ, Ricard, "De la opacidad a la casa de cristal. El conflicto entre privacidad y transparencia", Valero Torrijos, Julián y Fernández Salmerón, Manuel (coords.), Régimen Jurídico de la transparencia del sector público. Del derecho de acceso a la reutilización de la información, Aranzadi, Cizur Menor, 2014, pp. 241-280.

NIETO GARRIDO, Eva, "Transparencia y acceso a los documentos versus derecho a la protección de datos de carácter personal en la reciente jurisprudencia del TJUE", Piñar Mañas, José Luis, Transparencia, acceso a la información y protección de datos, Ed. Reus, Madrid, 2014, pp. 63-96.

PAREJO ALFONSO, Luciano, "El silencio administrativo, especialmente el de sentido estimatorio, como aporía. Apuntes de una posible vía de superación", Parejo Alfonso, Luciano, El silencio en la actividad de la Administración pública, Tirant lo Blanch, Valencia, 2011, pp. 11-32.

PELÁEZ MURAS, Manuel, "El acceso a la información ambiental en poder de la Administración regional: Seis notas prácticas y una dificultad superada en parte", Gabilex: Revista del Gabinete Jurídico de Castilla-La Mancha, núm. 8, 2016.

PEÑALVER I CABRÉ, Alexandre, "Novedades en el acceso a la justicia y a la tutela administrativa en asuntos medioambientales", Pigrau Solé, Antoni (dir.), Acceso a la información, participación pública y acceso a la justicia en materia de medio ambiente: diez años del Convenio de Aarhus, Atelier, Barcelona, 2008, pp. 349-403.

- "El derecho humano al medio ambiente y su protección efectiva", Revista Vasca de Administración Pública, núm. especial 99-100, 2014.

PIGRAU SOLÉ, Antoni (dir.), Acceso a la información, participación pública y acceso a la justicia en materia de medio ambiente: diez años del Convenio de Aarhus, Atelier, Barcelona, 2008. 
PIÑAR MAÑAS, José Luis, "Transparencia y protección de datos: las claves de un equilibrio necesario", Ruiz Ojeda, Alberto (coord.), El gobierno local. Estudios en homenaje al Profesor Luis Morell Ocaña, lustel, Madrid, 2010, pp. 1023-1044.

- "Transparencia y derecho de acceso a la información pública. Algunas reflexiones en torno al derecho de acceso en la Ley 19/2013, de Transparencia, Acceso a la Información y Buen Gobierno", Revista Catalana de Dret Públic, núm. 49, 2014.

- "Transparencia y protección de datos. Una referencia a la Ley 19/2013, de 9 de diciembre, de transparencia, acceso a la información y buen gobierno", Piñar Mañas, José Luis, Transparencia, acceso a la información y protección de datos, Ed. Reus, Madrid, 2014, pp. 45-62.

PRIEUR, Michel, "El proyecto de Pacto internacional sobre el derecho de los seres humanos al medio ambiente", Revista Aranzadi de Derecho Ambiental, núm. 38, 2017.

RAMS RAMOS, Leonor, "La transformación del derecho de acceso en España: de derecho de configuración legal a derecho fundamental", Revista Española de Derecho Administrativo, núm. 160, 2013.

- "El acceso a los sistemas de información geográfica y su reutilización", Valero Torrijos, Julián y Fernández Salmerón, Manuel (coords.), Régimen jurídico de la transparencia del sector público: del Derecho de acceso a la reutilización de la información, Aranzadi, Cizur Menor, 2014, pp. 587-629.

- "El procedimiento de ejercicio del derecho de acceso a la información pública", Revista General de Derecho Administrativo, núm. 41, 2016.

RAZQUIN LIZARRAGA, José Antonio, "El Convenio de Aarhus", Actualidad Jurídica Aranzadi, núm. 670, 2005.

- "Acerca de la naturaleza del derecho de acceso a la información pública (A propósito de la STEDH de 28 de noviembre de 2013)", Revista Aranzadi Doctrinal, núm. 11/2014.

RAZQUIN LIZARRAGA, José Antonio y RUIZ DE APODACA ESPINOSA, Ángel María, Información, Participación y Justicia en materia de medio 
ambiente. Comentario sistemático a la Ley 27/2006, de 18 de julio, Aranzadi, Cizur Menor, 2007.

RAZQUIN LIZARRAGA, Martín María, La confidencialidad de los datos empresariales en poder de las administraciones públicas (Unión Europea y España), lustel, Madrid, 2013.

- El derecho de acceso a la información pública: teoría y práctica, en especial, para las entidades locales, IVAP, Oñati, 2016.

RODRÍGUEZ ÁLVAREZ, José Luis, "Transparencia y protección de datos personales: criterios legales de conciliación", Canals i Ametller, Dolors (ed.), Datos. Protección, transparencia y buena regulación, Documenta Universitaria, Girona, 2016, pp. 53-85.

RUIZ DE APODACA ESPINOSA, Ángel María, "Transparencia empresarial e información ambiental", Sanz Larruga, Javier (dir.) y otros, Libre mercado y protección ambiental: intervención y orientación ambiental de las actividades económicas, INAP, Madrid, 2013, pp. 387-419.

SALAZAR ORTUÑO, Eduardo, "Transparencia y acceso a la información ambiental", Valero Torrijos, Julián y Fernández Salmerón, Manuel (coords.), Régimen jurídico de la transparencia del sector público: del Derecho de acceso a la reutilización de la información, Aranzadi, Cizur Menor, 2014, pp. 537-558.

SALLES CAVEDÓN, Fernanda de, "La construcción de una dimensión ambiental de los derechos humanos por la jurisprudencia de la Corte Europea de Derechos Humanos: el derecho de acceso a la información y a la libertad de expresión en materia ambiental", Revista Aranzadi de Derecho Ambiental, núm. 14, 2008.

SAN MARTÍN SEGURA, David, 'La 'ecologización' de los derechos fundamentales en el marco del Convenio Europeo de los Derechos Humanos", Revista de Derecho de la Universidad de La Rioja, núm. 3, 2005.

SANZ LARRUGA, Javier, "La administración electrónica como instrumento de protección ambiental. En particular, los servicios electrónicos de información ambiental (2003-2013)", Balcells Padullés, Joan y otros (coords.), Internet, derecho y política una década de transformaciones: Actas del $X$ Congreso 
Internacional Internet, Derecho y Política, Universitat Oberta de Catalunya, Barcelona, 2014, pp. 553-564.

SCHMIDT-ASSMANN, Eberhard, "Pluralidad de estructuras y funciones de los procedimientos administrativos en el Derecho alemán, europeo e internacional", Barnés, Javier (ed.), La transformación del procedimiento administrativo, Editorial Derecho Global, Sevilla, 2008, pp. 71-112.

SIMÓN YARZA, Fernando, "La construcción de la tutela ambiental en la jurisprudencia de Estrasburgo", Persona y Derecho, núm. 63, 2010

TRIAS PRATS, Bertomeu, "Veinticinco años de acceso a la información en Italia: de la Ley 349/1986 a la Directiva Inspire", Revista de Administración Pública, núm. 1888, 2012.

VARGA PASTOR, Aitana de la, "Estudio de la publicidad activa de la información pública: Especial referencia a la información ambiental y a la aplicación de la Ley 19/2013, de 9 de diciembre, de transparencia, acceso a la información pública y buen gobierno", Revista Catalana de Dret Ambiental, vol. 6, núm. 1, 2015.

VARGA PASTOR, Aitana de la y FUENTES I GASÓ, Josep Ramon, "Las autoridades públicas ante las nuevas obligaciones en materia de información ambiental. Especial referencia a la difusión de información ambiental", Pigrau Solé, Antoni (dir.), Acceso a la información, participación pública y acceso a la justicia en materia de medio ambiente: diez años del Convenio de Aarhus, Atelier, Barcelona, 2008, pp. 117-224. 